\title{
Hes6 acts in a positive feedback loop with the neurogenins to promote
} \section{neuronal differentiation}

\author{
Naoko Koyano-Nakagawa, ${ }^{1, *}$, Jaesang Kim ${ }^{2, *}$, David Anderson² and Chris Kintner ${ }^{1, \neq}$ \\ ${ }^{1}$ The Salk Institute for Biological Studies, PO Box 85800, La Jolla, CA 92186-5800, USA \\ 2Division of Biology 216-76, Howard Hughes Medical Institute, California Institute of Technology, Pasadena, CA 91125, USA \\ *These authors contributed equally to this work \\ ¥Author for correspondence (e-mail: Kintner@salk.edu) \\ Accepted 18 July; published on WWW 7 September 2000
}

\section{SUMMARY}

During the development of the vertebrate nervous system, neurogenesis is promoted by proneural bHLH proteins such as the neurogenins, which act as potent transcriptional activators of neuronal differentiation genes. The pattern by which these proteins promote neuronal differentiation is thought to be governed by inhibitors, including a class of transcriptional repressors called the WRPW-bHLH proteins, which are similar to Drosophila proteins encoded by hairy and genes in the enhancer of split complex (E-(SPL)-C). Here, we describe the isolation and characterization of Hes6, which encodes a novel WRPWbHLH protein expressed during neurogenesis in mouse and Xenopus embryos. We show that Hes6 expression follows

\section{INTRODUCTION}

Proteins belonging to the basic-helix-loop-helix (bHLH) family of transcription factors are instrumental in promoting cell differentiation during embryonic development. These proteins promote differentiation by forming heterodimers via the HLH domain with the ubiquitously expressed E-proteins, by binding via the basic domain to a DNA motif, the E-box, in the regulatory regions of target genes, and by activating transcription in part by recruiting co-activators that contain histone acetyltransferase activity. One subfamily of these bHLH proteins, which includes such members as MyoD (Myod1 - Mouse Genome Informatics), Myf5 and myogenin, are potent transcriptional activators of the myogenic program required for muscle-cell differentiation during myogenesis (reviewed in Yun and Wold, 1996). Muscle differentiation is blocked when the mouse myogenic bHLH genes are mutated by gene targeting, while a number of cell types can be converted into muscle cells by ectopic expression of these genes. Similarly, neurogenesis is promoted in ectodermal cells by another family of bHLH proteins that act as potent transcriptional activators of neuronal differentiation (reviewed in Lee, 1997). In vertebrates, the proneural bHLH proteins include the neurogenins, NeuroD (Neurod1 - Mouse Genome Informatics), Math1 and Math3 (Atoh1 and Atoh3 - Mouse that of neurogenins but precedes that of the neuronal differentiation genes. We provide several lines of evidence to show that Hes6 expression occurs in developing neurons and is induced by the proneural bHLH proteins but not by the Notch pathway. When ectopically expressed in Xenopus embryos, Hes6 promotes neurogenesis. The properties of Hes6 distinguish it from other members of the WRPWbHLH family in vertebrates, and suggest that it acts in a positive-feedback loop with the proneural bHLH proteins to promote neuronal differentiation.

Key words: Neurogenins, Mouse, Xenopus, Hes6, Differentiation
Genome Informatics), which are related to the Drosophila atonal, and Mash1 (Ascl1 - Mouse Genome Informatics), Xash3 or Cash4, which are related to Drosophila achaete (ac) and scute (sc). Targeted mutations in the proneural genes such as mouse Mash1, Ngn1 (Neurod3 - Mouse Genome Informatics), Ngn2 (Atoh4 - Mouse Genome Informatics) and Math1, lead to a block in neuronal differentiation (BenArie et al., 1997; Fode et al., 1998; Guillemot et al., 1993; Ma et al., 1998). Conversely, misexpression of these genes promotes ectopic neurogenesis, as seen for example when the neurogenins are ectopically expressed in chick, zebrafish, Xenopus embryos or in cell lines (Blader et al., 1997; Farah et al., 2000; Lee et al., 1995; Ma et al., 1996; Perez et al., 1999; Takebayashi et al., 1997).

Because the myogenic and proneural bHLH proteins are both necessary and sufficient to promote cell differentiation, the levels of their expression and/or activity are thought to be critical in determining patterns of cell differentiation during embryogenesis. As a consequence, factors that target either the expression or the activity of these proteins are likely to be responsible for regulating the spatial and temporal patterns of cell differentiation. One class of negative regulators is the Id-family of proteins that contain a helix-loop-helix domain but lack the basic, DNA-binding domain (Jen et al., 1992; Lyden et al., 1999; Van Doren et al., 1992). These proteins heterodimerize with the determinative bHLH proteins, thus 
displacing the ubiquitous E-proteins and forming inactive heterodimers that cannot bind DNA and activate gene expression. A second class of inhibitor includes molecules such as Twist, MyoR (Msc - Mouse Genome Informatics) and Zeb1, which inhibit myogenesis by either binding to Eboxes and displacing the myogenic proteins or by interfering with interactions between the myogenic bHLH proteins and Mef2, an obligatory co-factor for transcriptional activation at myogenic promoters (Lu et al., 1999; Postigo and Dean, 1997; Spicer et al., 1996). Finally, a third class of negative regulator consists of a subfamily of the bHLH transcription factors, whose members contain a conserved proline in the basic domain and a WRPW tetrapeptide at the $\mathrm{C}$ terminus that interacts with the co-repressor Groucho (Fisher and Caudy, 1998). The WRPW-bHLH proteins inhibit differentiation by acting as transcriptional repressors that antagonize the expression and/or activity of the positive-acting bHLH proteins. For example, in Drosophila the formation of sensory-organ precursors is driven by two proneural bHLH proteins, achaete and scute (Modolell, 1997). The transcription of the $a c$ and $s c$ genes within territories of the imaginal discs is repressed in part by the WRPW-bHLH protein hairy that interacts with $\mathrm{N}$-box binding sites present in their promoters. Similarly, the activity and expression of achaete and scute within the proneural cluster are also repressed by the process of lateral inhibition. This repression is mediated by the WRPW-bHLH proteins encoded in the $\mathrm{E}(\mathrm{spl})$-complex (E(SPL)-C), which are activated by the Notch signaling. In both of these examples, the WRPW-bHLH proteins act to antagonize achaete and scute by repressing their expression or their ability to activate target genes required for differentiation (Modolell, 1997).

Vertebrate genes have been identified that encode WRPWbHLH proteins similar to those encoded by Drosophila hairy and genes in the E(SPL)-C (Dawson et al., 1995; Jen et al., 1999; Sasai et al., 1992; Takke and Campos-Ortega, 1999; Takke et al., 1999; Wettstein et al., 1997). Functional analyses of these genes indicate that they antagonize the ability of the positive-acting bHLH proteins to regulate various aspects of cell differentiation and tissue patterning (Castella et al., 1999; Ishibashi et al., 1994, 1995; Nakamura et al., 2000; Strom et al., 1997; Takke et al., 1999). To identify additional vertebrate WRPW-bHLH genes that potentially regulate neuronal differentiation, degenerate PCR was used to amplify sequences encoding the HLH domains from mouse genomic DNA, yielding sequences encoding a novel WRPW-bHLH protein, called Hes6, which is expressed in both mouse and Xenopus embryos. In contrast to other Hes genes that are associated with the inhibition of neurogenesis, Hes6 expression in the developing nervous system in both species correlates with neurogenesis, following the expression of the neurogenins but preceding that of the differentiation genes. Several lines of evidence show that Hes6 is expressed in neuronal precursors, is activated by the proneural bHLH proteins, but is not induced by the Notch pathway. When ectopically expressed in Xenopus embryos, Hes6 promotes neurogenesis. The properties of Hes6 distinguish it from other members of the WRPW-bHLH family in vertebrates, and suggest that it acts in a positive-feedback loop with the proneural bHLH proteins to promote differentiation in the developing nervous system.

\section{MATERIALS AND METHODS}

\section{Isolation of murine Hes6}

A 197-base fragment encoding a portion of the Hes6 gene was isolated by amplifying genomic mouse DNA using PCR and the degenerate oligonucleotide primers (5'-TTTGAATTCAA $1 /{ }_{G} \mathrm{C} / \mathrm{ACIATIATGGA} / \mathrm{GAA}_{\mathrm{G}} \mathrm{A} / \mathrm{GAA}_{\mathrm{A}} 3^{\prime}$ encoding amino acids $\mathrm{K}^{\mathrm{P}} / \mathrm{T} / \mathrm{MMEK} / \mathrm{N}$ and $5^{\prime}$-CTTTCTAGAITCIGC $/ \mathrm{CTT}^{\mathrm{T}} / \mathrm{CTCIAG}^{\mathrm{T}} / \mathrm{CTT}$ $3^{\prime}$ corresponding to the complementary sequence coding for amino acids $\mathrm{KLEKA}^{\mathrm{E}} / \mathrm{D}$; the two primers contain EcoRI and XbaI sites at the $5^{\prime}$ and $3^{\prime}$ end, respectively). The presumptive partial cDNA sequence matched with several expressed sequence tag (EST) clones (e.g. GenBank accession numbers, W62881 and W66929) from which the full-length cDNA was derived. The Xenopus Hes6 cDNA was isolated by screening a stage $17 \mathrm{cDNA}$ library under moderate stringency.

\section{Embryos and injections}

Embryos were obtained from Xenopus laevis adult frogs by hormoneinduced egg laying and in vitro fertilization using standard methods. Xenopus embryos were staged according to (Nieuwkoop and Faber, 1967). Synthesis and injection of RNA was carried out as described previously (Kintner and Dodd, 1991). To examine embryos by in situ hybridization, 0.2-1.0 ng of test RNAs were injected into single blastomeres of albino embryos at the two-cell stage, along with a synthetic $n$-lacZ RNA (500 pg), encoding a nuclear-localized form of $\beta$-galactosidase. The number of embryos with a given phenotype and the total number scored for each injection are presented in the figure legends. For animal cap assays, both blastomeres of the two-cell stage embryos were injected in the animal region with 0.3-2.0 $\mathrm{ng}$ of the indicated synthetic RNAs. Templates for generating RNA encoding Notch-ICD, X-Su(H)DBM, XNGN1, XASH3, ESR7, ESR7 $\Delta \mathrm{b}$ and $\beta$ galactosidase are described in Chitnis et al., 1995; Coffman et al., 1993; Deblandre et al., 1999; Detrick et al., 1990; Ferreiro et al., 1994; Ma et al., 1996; Wettstein et al., 1997, respectively. Templates for Xenopus Hes6 were generated by amplifying the Hes6-coding regions using sense (5'-CTCCTCGAGCGCTCCATGTGTCCTTATTCATCT$\left.3^{\prime}\right)$ and antisense (5'-CATGAATTCCCATGCTCTTTATCCTTCATTTGG-3') primers, and cloning the resulting PCR product into the XhoI and the XbaI sites of pCS2(+) and pCS2(+)MT (Turner and Weintraub, 1994). pCS2(+)Hes6 6 WRPW was constructed with PCR using an antisense primer 5'-GGTGAATTCATAGTAGAAGCCGG$3^{\prime}$, thus, generating a deletion of the WRPW tetrapeptide at the C-terminus. pCS2(+)Hes6DBM was generated by site-directed mutagenesis using a primer 5'-ACAAGGAAACCTCTGGTTCGCGAGAGGGAAGAAGCTGACATAGATGAGAGCCTACAG $-3^{\prime}$. This mutation changes the amino acid sequence of the basic region from EKRRRARIN (positions 21 to 29) to REREEADID. cDNA encoding Xath3 was isolated by RT-PCR based on the published sequence (Takebayashi et al., 1997) and cloned into the EcoRI and the $X h o \mathrm{I}$ sites of pCS2(+) as well as pBS KS(-). The coding region of Xenopus $(X)$ hairy $2 a$ was amplified with primers EcoRI-MPADTM (5'-GATGAATTCATGCCCGCAGATACCATG-3') and StuIWRPWVS (5'-TTAGGCCTCCATGGTCTCCACACTGA-3'), and cloned into the EcoRI and StuI sites of pCS2(+) vector to produce pCS2(+)Hairy2A. In pCS2(+)Hairy2A-Gal4, the C-terminal WRPW tetrapeptide was deleted by PCR using antisense primer StuIVSEASD (5'-TTAGGCCTCACTGACTCAGCGCTGTC-3'), and replaced with the activation domain of yeast GAL4 protein.

\section{In situ hybridization}

Xenopus embryos were stained by whole-mount in situ hybridization according to (Harland, 1991) with modifications described by Knecht et al. (1995) using digoxigenin-labeled antisense riboprobes. Prior to in situ hybridization, injected embryos were stained for $\beta$ galactosidase activity with 5-bromo-4-chloro-3-indolyl-bgalactopyranoside (X-gal) (Detrick et al., 1990). In situ hybridization on frozen sections and whole-mount in situ hybridization for mouse 
samples were performed as previously described with minor modifications (Birren et al., 1993; Ma et al., 1998). Digoxigeninlabeled probes for mouse Ngnl (Ma et al., 1998), mouse NeuroD (Lee et al., 1995) and rat $S c g 10$ (Stein et al., 1988) used in this study have been previously described. The template for Sox10 probe has also been described (Kuhlbrodt et al., 1998). The probe template for mouse Hes6 was derived from an EST clone (GenBank accession number W62881) and includes 60 bases of 5' UTR and 530 bases of ORF. Plasmids used for generating in situ hybridization probes for Xenopus embryos are described in Dawson et al. (1995; Xhairy1); Schmidt et al. (1995; Xhairy2A); Brewster et al. (1998; Zic2); Mayor et al. (1995; Xslug); Good (1995; Elrc); Bellefroid et al. (1996; Xmyt1); Tracey et al. (1998; Xaml); Oschwald et al. (1991; N-tubulin); Ma et al. (1996; Xngn1); Deblandre et al. (1999; Esr7). Xdrebrin, Xnscl1 and Xmmot1 cDNAs were isolated during a screen for genes that are induced by Xngn1 (Deblandre et al., 1999), and will be described elsewhere. The amino acid sequence of Xnscl1 is $100 \%$ identical to Hen1 (Bao et al., 2000), and Xmmot1 is $98.0 \%$ and $97.5 \%$ identical to Xcoe2 (Dubois et al., 1998) and Xebf2 (GenBank accession number AF040993), respectively. Nucleotide sequence of Xdrebrin has been submitted to GenBank. For Xdrebrin, Xnscl1, and Xmmot1 probes, pBluescript SK(-) plasmids containing these cDNAs were digested with Notl and transcribed with $\mathrm{T} 7$ polymerase.

\section{Immunohistochemistry and X-gal staining}

Dorsal root ganglia (DRG) were microdissected from E12.5 embryo and dissociated in trypsin (0.05\%; Gibco-BRL). Cells were plated at 20,000 cells per $35 \mathrm{~mm}$ dish that had been treated with poly-D-lysine $(0.05 \mathrm{mg} / \mathrm{ml}$; Biomedical Technologies $)$ and fibronectin $(0.25 \mathrm{mg} / \mathrm{ml}$; Biomedical Technologies), and cultured in DMEM-high-glucose medium containing $10 \%$ FBS and $20 \mathrm{ng} / \mathrm{ml}$ of NGF. Cells were fixed in $4 \%$ paraformaldehyde, washed and blocked, and double labeled with anti- $\beta$-galactosidase antibody (see below) and anti-Brn3 mouse monoclonal antibody (1:4; Chemicon). Secondary antibodies used were goat anti-rabbit-IgG Alexa 488 and goat anti-mouse-IgG Alexa 568 (Molecular Probes). Staining of mouse embryos with X-gal was performed as described (Gerety et al., 1999). For anti- $\beta$-galactosidase antibody staining on frozen sections, embryos were fixed in $4 \%$ paraformaldehyde in PBS for 2 hours, and embedded in 30\% sucrose and OCT prior to sectioning. Rabbit polyclonal anti- $\beta$-galactosidase antibody $\left(5^{\prime}-3^{\prime}\right)$ was used at a 1:500 dilution followed by HRPconjugated goat-anti-rabbit antibody (Chemicon).

\section{Animal cap explants and RNase protection assay (RPA)}

Animal caps were isolated at stage $9 / 10$ and cultured at $20^{\circ} \mathrm{C}$ for 2 hours, until the control embryos reached stage 11. RNA was isolated from cultured animal caps using Tri Reagent (Molecular Research Center, Inc.) and assayed simultaneously for the levels of Xhairyl and Efl $\alpha$ RNA using RPA as described previously (Koyano-Nakagawa et al., 1999). A probe for Xhairyl was generated by linearizing pBSII SK(+) Xhairy1 with AvaII and transcribing with T7 polymerase. Protected fragments were resolved on denaturing gels that were subsequently fixed, dried and imaged on a Phosphor Imager (Molecular Dynamics). After subtraction of background, the values obtained for Xhairyl protected fragments were normalized by dividing by the values obtained for Efl $\alpha$ RNA for each sample.

\section{Protein expression and purification}

The TNT SP6-Coupled Reticulocyte Lysate System (Promega) was used to synthesize $\left[{ }^{35} \mathrm{~S}\right]$ Met-labeled Xhairy2A, Hes6 and E12 (Ferreiro et al., 1994) proteins. Glutathione S-transferase (GST) fusion constructs (Frangioni and Neel, 1993) of Hes6, Xhairy1 and Xhairy2A were generated by inserting the coding region of each protein into pGEX4T1. GST fusion proteins were induced in BL21 cells, and purified on glutathione-agarose as described (Frangioni and Neel, 1993). The purity and concentration of eluted proteins were checked by Coomassie staining of SDS-PAGE and by the
Bradford method (Bio-Rad Protein Assay, Bio-Rad) with BSA as a standard.

\section{Pull-down assays}

In vitro binding assay was performed as described in (Wettstein et al., 1997). Briefly, protein translated in vitro $(1 \mu \mathrm{l})$ was first pre-cleared by incubating with GST bound to glutathione-agarose (GA) beads in $500 \mu \mathrm{l}$ of binding buffer $(10 \mathrm{mM}$ sodium phosphate $\mathrm{pH} 7.5,135 \mathrm{mM}$ $\mathrm{KCl}, 0.1 \%$ Triton X-100, $1 \mathrm{mM}$ DTT, $1 \mu \mathrm{M}$ Pepstatin, $1 \mu \mathrm{M}$ Leupeptin, $0.1 \mathrm{mM}$ PMSF and $5 \mathrm{mM} \mathrm{MgCl} 2$ ). Pre-cleared labeled proteins were then incubated with equal masses of fusion proteinsagarose beads, as judged by Coomassie staining, for each binding reaction. The binding reactions were incubated for 1 hour at room temperature. Beads were washed twice with binding buffer, heated in Laemmli buffer, electrophoresed on a $10 \%$ polyacrylamide gel and processed for autoradiography.

For in vivo binding experiments, synthetic RNA encoding indicated proteins were co-injected into the embryos and animal caps were isolated. Cell extracts were prepared in binding buffer described above, and incubated with Ni-agarose beads. The beads were then washed, and bound proteins visualized by western blotting using an anti-Myc monoclonal antibody (9E10) and chemiluminescence (Amersham).

\section{Electrophoretic mobility shift assay (EMSA)}

Sequences including an N-box from the Drosophila achaete promoter and an E-box from the muscle creatine kinase promoter were used as probes. Oligonucleotide sequences are as follows (the $\mathrm{N}$ - and E-boxes are underlined and mutated nucleotides are shown in bold).

Wild-type $a c$ h/E-1: 5'-CTAGAGCCGGCACGCGACAGGG-3'; 3'-TCGGCCGTGCGCTGTCCCGATC-5'

Mutant $a c$ h/E-1: 5'-CTAGAGCCGGGACGCGACAGGG-3'; 3'TCGGCCCTGCGCTGTCCCGATC-5'

MCK E-box: 5'-CTAGCCCCCAACACCTGCTGCCTGA-3'; 3'GGGGGTTGTGGACGACGGACTGATC-5'

Both ends of the annealed oligonucleotides were radiolabeled by Klenow reaction. Labeled probe was purified on a $12 \%$ acrylamide gel, and eluted in $200 \mu \mathrm{l}$ of $100 \mathrm{mM} \mathrm{KCl}, 1 \mathrm{mM}$ EDTA. Fifteen microliter total of binding reaction included $20 \mathrm{ng}$ to $400 \mathrm{ng}$ of GSTfusion protein or $5 \mu \mathrm{l}$ of in vitro translated protein, $25 \mathrm{mM}$ HEPES$\mathrm{KOH}$ (pH 7.5), $50 \mathrm{mM} \mathrm{KCl,} 0.1 \mathrm{mM}$ EDTA, 0.1\% NP40, $100 \mathrm{ng}$ poly(dAdT), $7 \%$ glycerol, and $0.5 \mathrm{ng}$ of radiolabeled probe (approx. 50,000 c.p.m.). $10 \mathrm{ng}$ of unlabeled nucleotides were used as competitors where indicated. The binding reaction was incubated at room temperature for $30 \mathrm{~min}$ and loaded on a 5\% nondenaturing gel. Electrophoresis was carried out in $0.5 \times \mathrm{TBE}$ at room temperature at $15 \mathrm{~V} / \mathrm{cm}$.

\section{RESULTS}

\section{Isolation of cDNAs encoding mouse and Xenopus Hes6}

Sequences encoding mouse Hes6 were isolated from genomic DNA using degenerate PCR with primers corresponding to conserved sequences within the helix-loop-helix domain (see Materials and Methods). A full-length cDNA encoding mouse Hes6 predicts a protein of 224 amino acids with all the structural features of a subfamily of bHLH proteins that act as transcriptional repressors (Fisher and Caudy, 1998), namely a conserved proline in the basic domain and a C-terminal WRPW tetrapeptide that interacts with the Groucho-like corepressors (Fig. 1). The mouse Hes6 cDNA was used to screen a stage-17 Xenopus cDNA library under moderate stringency, yielding a clone that encodes a protein very related to mouse 
Hes6. The Xenopus and mouse Hes6 proteins define a subfamily that is distinct from the other known WRPW-bHLH proteins (Fig. 1B). One defining feature of this subfamily is a particularly small loop region in the bHLH domain (Fig. 1C). As the loop region has been implicated in the interactions of these proteins with DNA binding sites, we tested whether Hes6 recognizes the same N-box sequence as other hairy-like bHLH proteins. While both Xhairy2A and Xhairy1 shift a N-box sequence in an EMSA, no detectable binding was observed with Hes6 (Fig. 1D). Similarly, Xenopus E12 but not Hes6 shifts an E-box sequence in an EMSA(Fig. 1D). We conclude that mouse and Xenopus Hes6 are likely to be homologs, and they define a new subfamily of the WRPW-bHLH proteins in vertebrates with different DNA-binding properties.

\section{Expression of Hes6 during neurogenesis in mouse and Xenopus}

The role of Hes6 in embryonic development was examined initially by localizing the expression of Hes6 RNA in Xenopus and mouse embryos at various developmental stages using whole-mount in situ hybridization. In mouse embryos, Hes6 expression was first noted in the midbrain (Fig. 2A) and the primordia of the cranial sensory ganglia at embryonic day (E) 8.75. By E9.25, expression was also seen in dorsal root ganglia (DRG) (Fig. 2B) and by E9.5 in other developing neural tissues

Fig. 1. Xenopus and mouse Hes6 define a new family of WRPW-bHLH proteins. (A) Mouse (m) and Xenopus (x) cDNAs encode related WRPW-bHLH proteins with $72 \%$ sequence identity in the bHLH domains and $52 \%$ overall. (B) Alignment of the basic helix-loop-helix regions of the WRPW-bHLH proteins shown in C. Residues identical to those in mouse Hes6 are boxed. Note the overall higher level of sequence similarity between mouse and Xenopus Hes6 relative to the other WRPW-bHLH proteins, and the shorter loop domain. (C) Sequence similarity tree showing the relationship of Xenopus and mouse Hes6 to other WRPW-bHLH proteins identified in Xenopus (xEsr1, 4, 5, 6e and 7, Xhairy1 and Xhairy2a), rat (r) (Hes1 and Hes5), chick (cHairy1) and Drosophila (Dm) hairy, and Esplm8). Note that mouse and Xenopus Hes6 define a new subfamily. (D) Lanes 1-9, Hes6, Xhairy1 and Xhairy2A were expressed in bacteria as GST fusion proteins and purified by affinity chromatography on glutathioneagarose beads. $150 \mathrm{ng}$ of each protein was mixed with a

${ }^{32} \mathrm{P}$ labeled oligonucleotide containing an N-boxbinding site (Van Doren et al., 1994). For competition, each reaction included a 20 -fold excess of unlabeled oligonucleotide, either wild type (wt) or mutant (mu) (see Materials and Methods). Up to $2 \mu \mathrm{g}$ of Hes6 tested in this assay failed to give detectable binding. Lanes 1012; in vitro translated Hes6 (lane 11) and E12 (lane12) proteins were mixed with an E-box probe. Closed arrow denotes specific binding by the E12 protein. Open arrows indicate nonspecific shift, which is also observed in mock translated extract (lane 10).
A

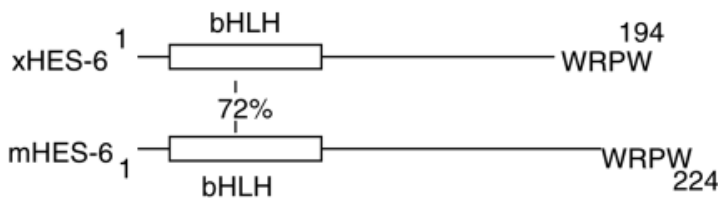

B

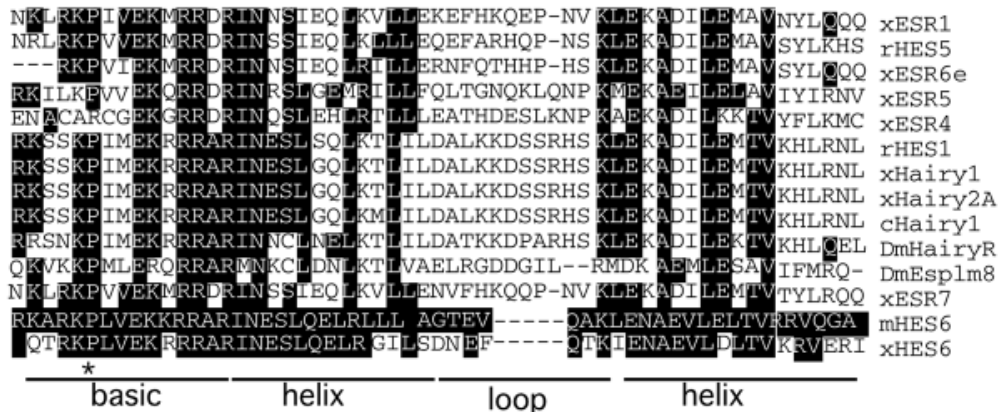

C

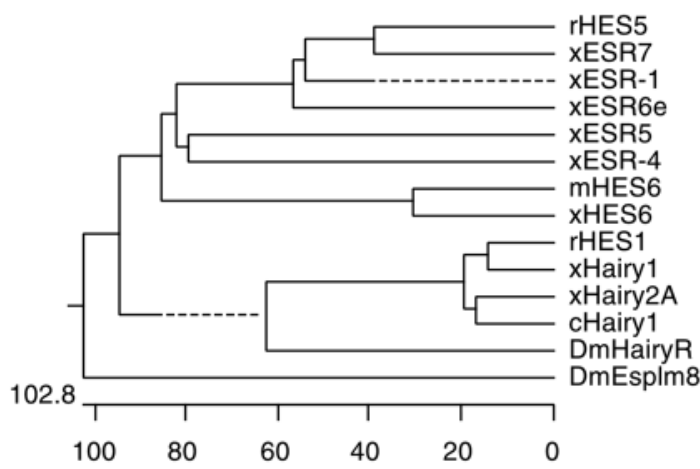

D

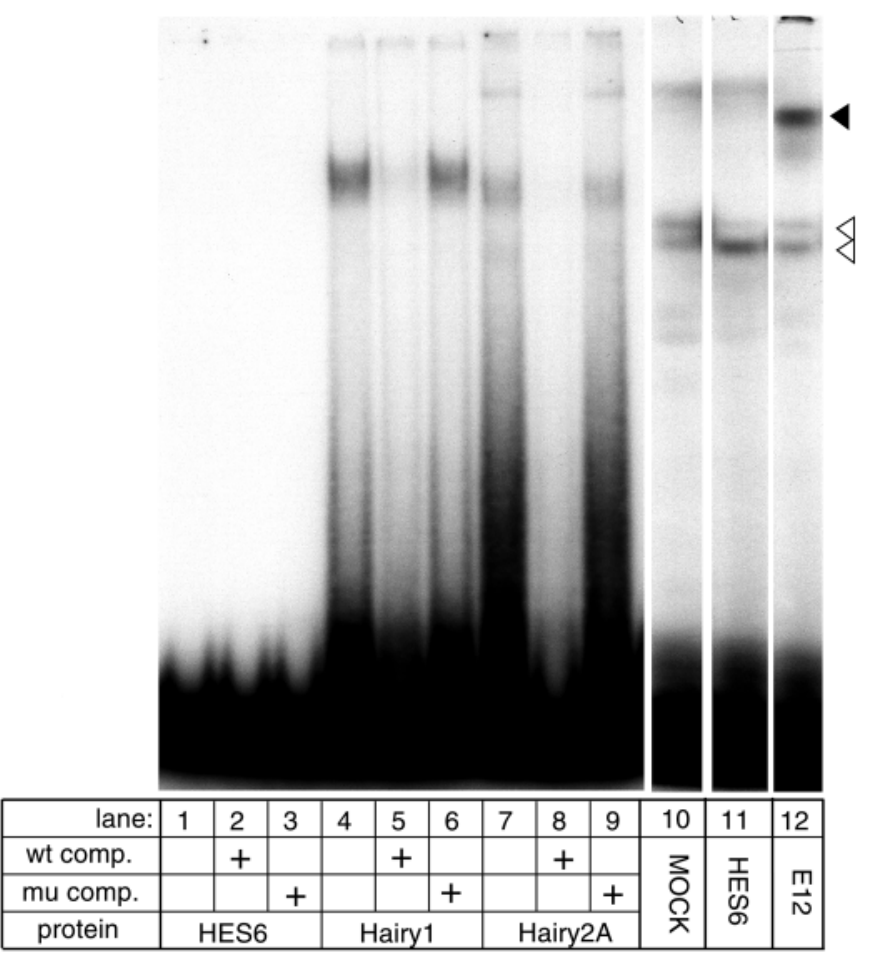


including the hind brain and neural tube (Fig. 2C). Expression of Hes6 in developing DRG appeared to increase further at E10.5 (Fig. 2D), paralleling neuronal differentiation. Sections of a whole-mount embryo at E10.5 showed expression in all neural tissues including specific regions of the hindbrain, forebrain and neural tube (Fig. 2E,F and data not shown). Hes6 expression was also detected in sympathetic ganglia, olfactory epithelium and the eye at later stages (data not shown)

The expression of Hes6 in the nervous system appears to exhibit spatial and temporal restrictions. For example, crosssections of the neural tube at E10.5 show that, as in the case of Xenopus (Fig. 2P), the highest level of expression is in the intermediate zone between the ventricular zone and the marginal zone where terminally differentiated neurons are found (Fig. 2E,I). This pattern is similar to that of NeuroD (Fig. $2 \mathrm{H}$ ) but is distinct from that of $\mathrm{Ngnl}$ (Fig. 2G) which is expressed in both the ventricular and intermediate zones and from $\operatorname{Scg} 10$ (Fig. 2J) which identifies the terminally differentiated neurons in the marginal zone of the neural tube. This spatial pattern of Hes6 expression in the neural tube suggests that it is temporally downstream of Ngnl and upstream of $S \operatorname{cg} 10$ and relatively synchronous with NeuroD. Consistent with this, expression in the DRG shows a rostralto-caudal gradient of expression, which closely matches that of NeuroD and precedes that of ScglO (Fig. 2K-M).

In addition to its expression in the nervous system, Hes6 is also expressed in mesodermal derivatives. Starting at E9.75 (27 somites), expression is seen in the somites (Fig. 2D,K). The expression in the somites seems to be restricted to myotomal cells, as Hes6 expression is seen later only in the skeletal muscles among the paraxial mesoderm derivatives (data not shown). Hes6 expression was also detected in the thymus and pancreas starting at E13.5 (data not shown). The expression of Hes6 outside the nervous system will be described in detail elsewhere.

Hes6 expression in Xenopus mirrors that in the mouse, suggesting that many aspects of its expression pattern are conserved in evolution. As in the mouse, Hes6 expression is prominent in the developing nervous system with low levels of Hes6 staining first appearing at neural plate stages, in scattered cells located within the three longitudinal domains of the neural plate where the primary neurons form (Fig. 2N). The timing of the expression in the neural plate follows that of Xngn 1, and precedes that of N-tubulin, a marker of differentiated neurons (Ma et al., 1996). This expression persists as the neural plate forms the neural tube, and is localized to the cells lying in the position of the primary neurons at early neurulae stages (data not shown). By late neurulae stages, expression of Hes6 is prominent in sites of secondary neurogenesis in the eye and in the brain (Fig. 2O). Sections through late neurulae stage embryos indicated that staining for Hes6 is absent from the roof and floor plates, as well as from the regions of the neural tube where differentiated neurons lie (Fig. 2P). In addition, while expression of Hes6 occurs in the ventricular zone at low levels, higher levels of expression are detected in the intermediate zone where newly differentiating neurons are located. Thus, Hes6 expression in Xenopus, as in the mouse, is correlated with regions of the neuroepithelium where neurogenesis takes place and moreover occurs transiently in differentiating neurons or their precursors. Expression of Hes 6 also occurs in the mesoderm in a posterior domain that overlaps with the expression of genes involved in myogenesis and segmentation (Fig. 2O). This other expression domain will be described in detail elsewhere.

\section{Regulation of Hes 6 expression by the proneural and neurogenic genes}

During primary neurogenesis in Xenopus, the expression of the E(SPL)-related, WRPW-bHLH genes such as ESRI and ESR7 are activated principally by the $\mathrm{Su}(\mathrm{H})$-dependent Notch pathway (Deblandre et al., 1999; Koyano-Nakagawa et al., 1999; Wettstein et al., 1997). To determine whether Hes6 expression is also regulated by Notch signaling, we examined Hes6 expression in embryos expressing an activated form of the Notch receptor. RNA encoding just the intracellular domain of Xnotch1 (ICD) was injected into the animal pole of one blastomere at the two-cell stage, along with RNA encoding $\beta$ galactosidase (nlacZ) as a tracer (Chitnis et al., 1995). At neural plate stages, the injected embryos were fixed, reacted with X-gal, which stains the injected side blue, and then stained for Hes6 RNA expression by whole-mount in situ hybridization. In contrast to Notch target genes such as Esr 7 (Fig. 3B), the expression of Hes6 was not induced by ICD: expression in the posterior mesoderm was unchanged while that in the neural plate was lost (Fig. 3A). In addition, expression of Notch target genes during primary neurogenesis is lost in embryos expressing a DNA-binding mutant of Xenopus $\mathrm{Su}(\mathrm{H})\left(\mathrm{Su}(\mathrm{H})^{\mathrm{DBM}}\right)$ (Wettstein et al., 1997). In direct contrast, the expression of Hes6 did not change in levels in response to $\mathrm{Su}(\mathrm{H})^{\mathrm{DBM}}$ but did occur in more cells than normal (data not shown). In sum, these results show that Hes6 does not behave as a target of the Notch pathway in either the posterior mesoderm or the neuroepithelium, but does appear to be expressed in differentiating neuronal precursors, which change in number when the levels of Notch signaling are changed experimentally (Chitnis et al., 1995).

To examine further the relationship of Hes6 to neuronal differentiation, we determined whether its expression is induced by the positive-acting bHLH transcription factors that are known to promote neuronal differentiation in Xenopus embryos. These bHLH proteins act in genetic cascades beginning with Xngnl, a member of the neurogenin subfamily of atonal-like bHLH proteins whose expression prefigures where primary neurons will form (Ma et al., 1996). Genes encoding other atonal-like bHLH proteins such as NeuroD and Xath3 are expressed after Xngnl, and activated by ectopic Xngn1 expression (Ma et al., 1996; Takebayashi et al., 1997). Injecting RNA encoding Xngn1 produced a dramatic upregulation of Hes6 expression both in the neural plate as well as in the non-neural ectoderm, indicating that it activates Hes6 expression (Fig. 3C). Xath3 also induces Hes6 expression although not to the same levels seen with Xngn1 (data not shown). Significantly, ectopic expression of Xash3, a proneural bHLH gene related to Drosophila achaete and scute, also induced ectopic expression of Hes6 in the neural plate in a fairly uniform fashion (Fig. 3D, see Discussion). Thus, these results show that Hes6 expression can be promoted by the bHLH proteins.

To determine whether Hes6 expression requires the neurogenins, we examined mouse Hes6 expression in mutants of neurogenin 1 (Ngn1). To do this, a tau-lacZ indicator gene (Mombaerts et al., 1996) was fused in frame with the initiation 
Fig. 2. Expression of Mouse and Xenopus Hes6 during embryogenesis. (A-F) Hes6 RNA expression in Mouse embryos. (A) Expression is first seen at E8.75 in the midbrain

(A, arrowhead) and primordia of sensory cranial ganglia (arrows). (B) Expression in DRG is noted at E9.25 (arrow). (C) By E9.5, Hes6 is expressed in the hindbrain and neural tube (arrowheads), and expression in DRG is clearly established (arrow). (D) By E10.5, extensive expression of Hes6 occurs in the DRG indicated by arrow and somite by arrowhead. (E) Expression of Hes6 in the intermediate zone in the neural tube (arrowhead; arrow points to DRG) and (F) in subregions of hindbrain (arrow points to Hes6expressing cells and arrowhead indicates ventricular side) is shown in E10.5 embryo sectioned following whole-mount in situ hybridization. (G-J) In situ hybridization of adjacent sections at the hindlimb level of a E10.5 mouse embryo. Expression of NeuroD $(\mathrm{H}$, arrowhead) and Hes6 (I, arrowhead) overlaps with that of $\mathrm{Ngnl}(\mathrm{G})$ but is highest in the region adjacent to marginal zone where terminally differentiated neurons are marked by SCG10 (J, arrowhead). (K-M) Mouse embryos at 28-somite stage were probed with Hes6 (K), NeuroD (L), and Scg10 (M). The 12 th DRG for each of the embryo is indicated by the arrows. Note that expression of Hes6 and NeuroD precedes that of $S c g 10$ by three to four somites. Note also expression of Hes6 in the somites at this stage (K; arrowhead).

(N-P) Hes6 RNA expression was localized in Xenopus embryos by whole-mount in situ hybridization. (N) Expression of Hes6 in the nervous system is first detected at open neural plate stages in scattered cells within the three domains where primary neurons form, including a medial domain (m) corresponding to motoneurons, and a lateral domain (l) corresponding to sensory neurons. (O) By late neurulae stages, higher levels of Hes6 expression are detected during secondary neurogenesis in the brain (arrow) and eye (arrowhead). Note also the expression of Hes6 in the tailbud domain (TBD). (P) Tissue section of late neurulae embryo at the level of the hindbrain (otic vesicle: OV) shows extensive Hes6 expression within the intermediate zone of the neural tube along the entire dorsal ventral axis but excluded from the floor plate (fp) and roof plate. codon of Hes6 replacing one allele of the endogenous gene, using homologous recombination in mouse embryonic stem cells. The expression pattern of $\beta$-galactosidase in heterozygous embryos (Hes $6^{\text {tlacZ/+ }}$ ) was indistinguishable from that shown by RNA in situ hybridization, except for a slight lag in the $\beta$-galactosidase activity compared with Hes6 transcript (data not shown). This delay most probably reflects the time required for the translated product to accumulate to a detectable quantity. Homozygous animals (Hes6 $6^{\text {tlacZ/tlacZ }}$ or $H e s 6^{-/}$) are grossly normal with no apparent abnormalities in the Hes6 expressing tissues. More detailed phenotypic analysis of the homozygous mutants is currently in progress.

Hes $6^{\text {tlacZ/+ }}$ mice were crossed with mice heterozygous for Ngnl $\left(\mathrm{Ngnl}^{+/-}\right)$(Ma et al., 1998) to generate double heterozygotes that were then intercrossed to generate embryos with various genetic combinations of the two genes. At E10, proximal and distal cranial ganglia are clearly marked by $\mathrm{X}$ gal staining in the $\mathrm{NgnI}^{+/-}$; Hes ${ }^{\text {6tlacZ/tlacZ }}$ control embryos (Fig. 3E) while in the Ngnl homozygous mutant background, staining for $\mathrm{X}$-gal was missing specifically in the proximal cranial ganglia whose development is dependent on Ngnl (Fig.
3F) (Ma et al., 1998). One explanation for this observation is that Hes6 is a downstream target of Ngn1. However, it can also be explained by the loss of precursor cells that generate these ganglia. In order to distinguish between these possibilities, the trigeminal ganglion primordia were examined using Sox10 as a marker of neural crest cells (Kuhlbrodt et al., 1998). At embryonic day 9.5 (25 somites), Sox10 expression was detected in the trigeminal ganglion anlagen of both $\mathrm{NgnI}^{+/-}$; $\mathrm{Hes}^{\text {tlacZ/tlacZ }}$ and $\mathrm{NgnI}^{-1-}$; Hes $6^{\text {tlacZ/tlacZ }}$ embryos, while $\beta$ galactosidase was detected only in the former embryo (Fig. 3G$\mathrm{J})$. Thus, the absence of $\beta$-galactosidase in the proximal cranial ganglia of $\mathrm{Ngn1}^{-1-}$; Hes $6^{\text {tlacZ/tlacZ }}$ embryo probably reflects a lack of Hes6 expression in $\mathrm{NgnI}^{-/-}$mutants, rather than simply a lack of Hes6-expressing cells. Taken together with the fact that ectopic expression of $\mathrm{Ngnl}$ promotes ectopic expression of Hes6 in Xenopus, these loss- and gain-of-function data suggest that Hes 6 is a direct or indirect downstream target of Ngn1.

The expression of Hes6 in both mouse and Xenopus appears to be under the control of the neurogenins, and not lateral inhibition, suggesting that it functions in neuronal precursors 
Fig. 3. Regulation of Hes6 expression in Xenopus and mouse embryos (A-D) Xenopus embryos were injected with RNA encoding ICD (A,B), Xngn1 (C) or Xash3 (D), at the two-cell stage along with lacZ RNA as a tracer. At neural plate stages the embryos were fixed, stained for X-gal, which produces a lightblue reaction product, and for the expression of Hes6 (A,C,D) or Esr7 (B) by whole-mount in situ hybridization, which produces a dark blue-purple staining pattern. Shown are dorsal views with the injected side oriented up, and anterior to the left. Note that both Xngnl (39/41embryos) and Xash3 (50/51 embryos) induce the expression of Hes6, and that ICD induces the expression of Esr7 but not that of Hes6. (E-J) Requirement of Ngn1 for Hes6 expression in proximal cranial ganglia. (E) $\mathrm{NgnI}^{+/-} ; \mathrm{Hes}^{\text {tlacz/tlac } \mathrm{Z}}$ embryo at E10 shows staining for X-gal in both proximal (arrowheads) and distal ganglia (arrows).

(F) $\mathrm{Ngn1}^{-1-} ; \mathrm{Hes}^{\text {tlacz } \text { tlacZ }}$ embryo shows staining only in the

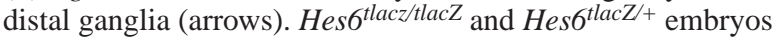
show identical X-gal staining patterns (data not shown).

(G-J) Adjacent transverse sections of $\mathrm{NgnI}^{+/-} ; \mathrm{Hes}^{\text {tlacZ/+ }}$ embryo (G and I) and Ngn1 $^{-1-} ;$ Hes $^{\text {tlacZ/+ }}$ embryo (H and $\mathrm{J}$ ) at E9.5 are shown. Trigeminal neural crest cells are visualized by Sox10 in both embryos ( $\mathrm{G}, \mathrm{H}$; arrows), but $\beta$-galactosidase is detected only in the $\mathrm{NgnI}^{+/-} ; \mathrm{Hes}^{\text {tlacZ/+ }}$ embryo (I,J; arrows).
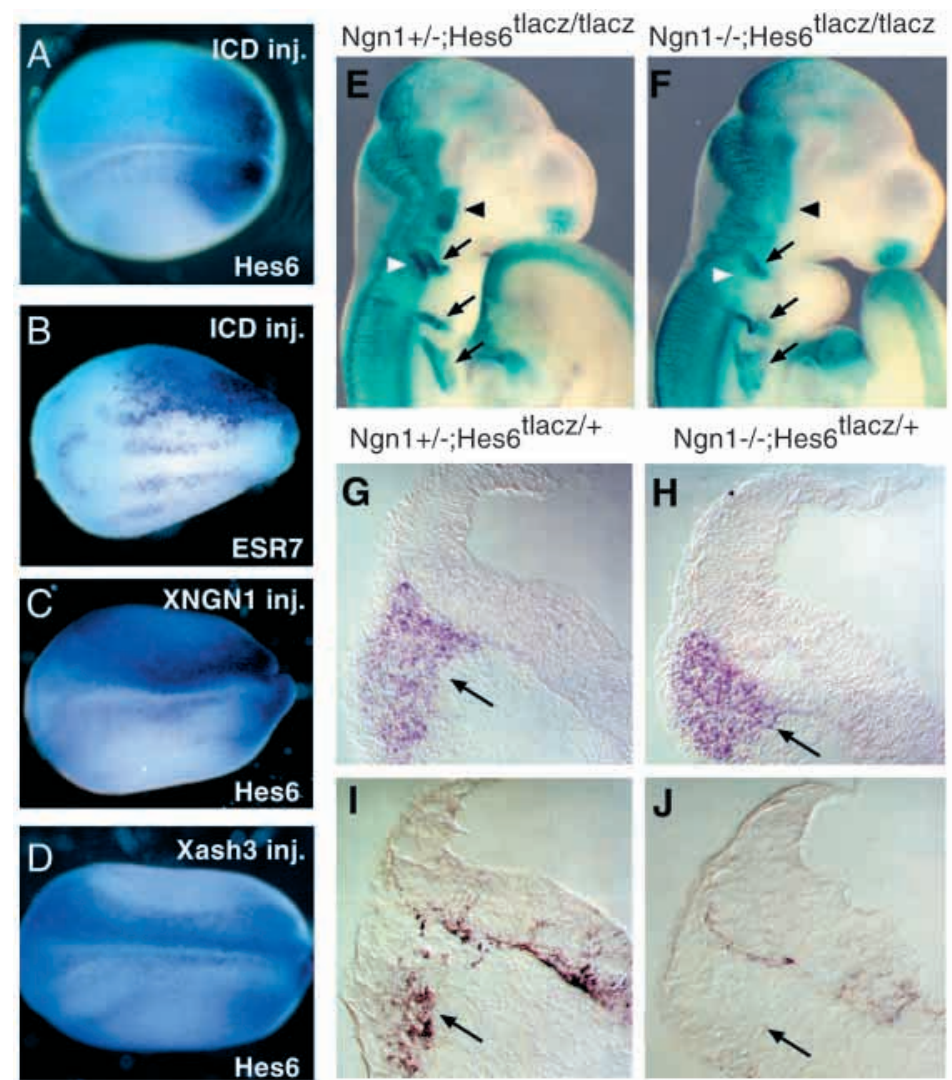

that undergo neuronal differentiation. To examine this possibility further, we determined the fate of Hes6-expressing cells in the mouse using the pattern of tau-lac Z expression in whole-mounts of Hes6 $6^{\text {tlacZ/+ }}$ embryos. This analysis shows that the lac $Z$ reporter is abundant in nerve fibers, as shown in sections from a heterozygous embryo stained with anti- $\beta$ galactosidase antibody (Fig. 4A,B). Given that Hes6 transcripts were detected prior to terminal differentiation in the neural tube, this pattern most probably reflects the perdurance of axon-targeted tau-lacZ $\mathrm{Z}$ product and is consistent with the idea that Hes6 expression occurs in the neuronal precursors. However, it was also possible that Hes6 was expressed in Schwann (glial) cells closely associated with nerve fibers. To address this, cultured cells isolated from DRG of E12.5 $H e s 6^{\text {tlacZ/+ }}$ embryos were double-labeled with antibodies to $\beta$ galactosidase and Brn3, a specific marker for sensory neurons and their immediate precursors (Fedtsova and Turner, 1995; Xiang et al., 1995). Virtually all $\beta$-galactosidase-positive cells were also positive for Brn3, confirming that Hes6 is expressed in neuronal precursors (Fig. 4F). Notably, non-neuronal cells from the ganglia, which probably represent satellite glia and their precursors, did not express $\beta$-galactosidase (Fig. 4C; see also 4D-F).

In sum, the expression data from both the mouse and Xenopus suggest that Hes6 is activated by the proneural genes during the determinative phase of neurogenesis. The protein is thus likely to function in progenitor cells as they make the transition into differentiated neurons.

\section{Hes6 activity promotes neuronal differentiation}

To test the role of Hes6 in the differentiation of neuronal precursors, Xenopus embryos were injected with Hes6 RNA at the two-cell stage, and then assayed at neural-plate stages for the expression of various genes associated with neuronal differentiation. In embryos injected with Hes6 RNA, the number of cells expressing $N$-tubulin, an early neuronal differentiation marker, is markedly increased, indicating that Hes6 induces neuronal differentiation (Fig. 5G). The cells induced by Hes6 express a panel of genes that are known to be activated by Xngn1 and associated with neuronal differentiation, including Xmyt1, Nscl1, Xmmot1, Elrc, drebrin (Fig. 5), as well as Xath3 and NeuroD (data not shown). Finally, ectopic expression of Hes6 also increased the number of cells expressing Xaml, a gene whose expression is restricted to a subset of cells in the lateral domain of the neural plate where sensory neurons form (Tracey et al., 1998) (Fig. 5E). These results indicate that Hes6 activity promotes neuronal differentiation within proneural domains, and contrast those obtained with other WRPW-bHLH proteins such as Esr7, Hes1 and Her4 which inhibit neuronal differentiation when misexpressed (Ishibashi et al., 1994; Takke et al., 1999).

Significantly, the regions of the neural plate where Hes6 RNA injection induces neuronal differentiation correspond closely to those previously defined as proneural domains based on the expression pattern of Xngnl (Ma et al., 1996). These regions include the posterior neural plate where primary neurons form in a pattern of stripes and the anterior placodes where neurons differentiate to form the trigeminal ganglia. The implication of this finding is that Hes6 primarily functions by promoting the differentiation of neuronal precursors that express Xngn1. Moreover, in Hes6 RNA injected embryos, the expression of Xngnl in the posterior neural plate becomes uniform, taking on a pattern that now prefigures the more uniform differentiation of neurons across the posterior neural 

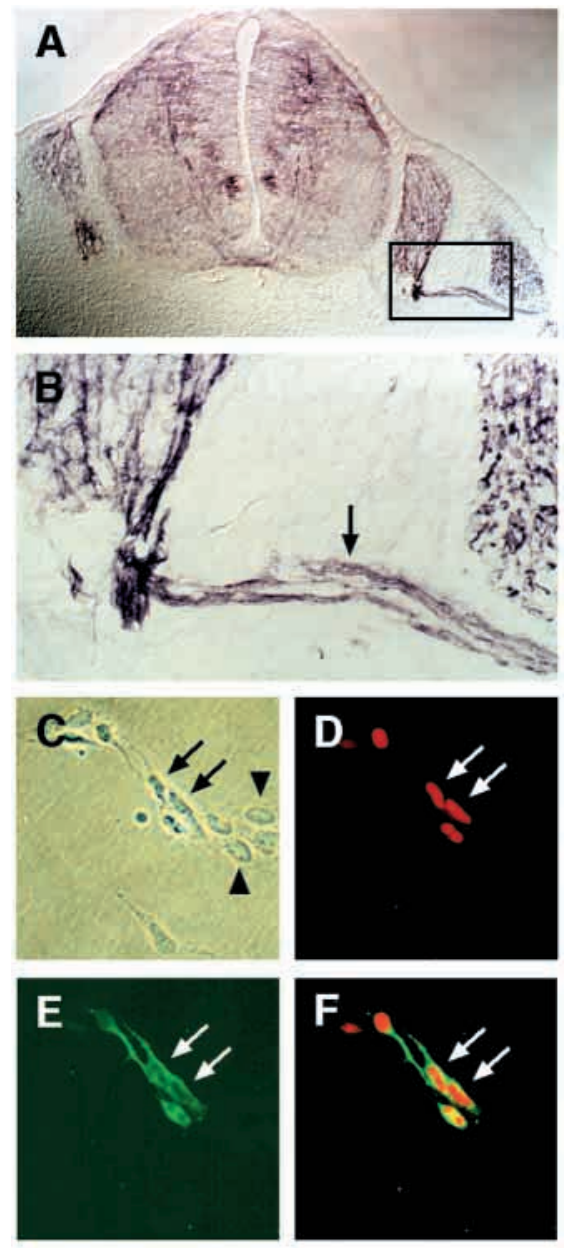

Fig. 4. Expression of Hes6 in the neuronal precursors. (A,B) Sections derived from Hes6 $6^{\text {tlacZ/+ }}$ embryo at E12.0 were labeled with anti- $\beta$ galactosidase antibody. A section at the forelimb level shows staining in neuronal fibers. A positive region in A (boxed) is shown in enlarged form in B (arrow). (C-F) DRG cells from a Hes6 $6^{\text {tlacZ/+ }}$ embryo at E12.5 were double labeled for Brn3 (D; red) and $\beta$ galactosidase (E; green). $\mathrm{C}$ shows the phase-contrast image of the field. Co-expression is seen in several cells $(\mathrm{F})$. Arrows indicate two of the double-positive cells (C-F), and arrowheads indicate two of the double-negative cells (C), which are probably satellite glia.

plate (Fig. 5H). This finding indicates that Hes6 may also promote neuronal differentiation by increasing the expression of Xngnl during the determinative phase of neurogenesis.

\section{Hes6 does not repress the expression of other WRPW-bHLH genes}

The model suggested by the results described above is that Xngn 1 activity promotes the expression of Hes6, which in turn promotes the differentiation of neuronal precursors. Because Hes6 has the structural features of a transcriptional repressor, we next considered the possibility that it inhibits the expression of factors that negatively regulate neuronal differentiation. In this context, Hes6 could conceivably repress the expression of genes required for lateral inhibition, a mechanism in which the Notch signaling pathway inhibits, via local cell-cell interactions, both the expression and activity of Xngn1, thus producing a salt-and-pepper pattern of neuronal differentiation
(Ma et al., 1996; Wettstein et al., 1997). Indeed, this possibility is supported by the finding that Hes6 induces a higher density of neuronal differentiation within the neural plate in a manner similar to that seen when Notch signaling is inhibited experimentally (compare Fig. 5I with Fig. 5A-G). However, the expression of the Notch ligand Xdeltal, and two Notch target genes Esrl and Esr7 (Chitnis et al., 1995; Deblandre et al., 1999; Wettstein et al., 1997) is not repressed by Hes6 but rather expands within the proneural domains, similar to the expansion seen for the neuronal differentiation genes described above (data not shown). This result indicates that Hes6 does not promote neuronal differentiation by transcriptionally repressing the expression of genes underlying lateral inhibition.

We next examined whether Hes6 might act by inhibiting the expression of repressors that are thought to inhibit neuronal differentiation during primary neurogenesis in the so-called interstripe regions. This analysis was motivated by the finding that Hes6 induces ectopic expression of Xngnl as well as ectopic differentiation of neurons over a much larger domain of the posterior neural plate than that observed in embryos where lateral inhibition is blocked (Fig. 5G). This finding is an indication that Hes6 may not only block inhibitors of neuronal differentiation that operate within the stripes, such as lateral inhibition, but also those operating between the stripes. Potential interstripe inhibitors include a krüppel-like $\mathrm{C}_{2} \mathrm{H}_{2}, \mathrm{Zn}$ finger transcription factor called Zic2 (Brewster et al., 1998), and the two hairy-like genes in Xenopus called Xhairyl and Xhairy2A (Dawson et al., 1995). In embryos injected with Hes6 RNA, the expression of Zic2 was unaffected, indicating that a loss of Zic2 expression cannot underlie the effects of Hes6 on neuronal differentiation (Fig. 6A). By contrast, the expression of hairy genes were strikingly altered in these embryos: the levels of both Xhairy $2 A$ and Xhairyl increased dramatically but only in the domains where these genes are normally expressed (Fig. 6B,C). Finally, we tested whether Hes6 acts in part by converting neural crest cells into neurons, by examining the expression of the neural crest marker, slug. Slug expression however was unchanged in response to Hes6 (Fig. 6D). Together these results suggest that Hes6 does not promote neuronal differentiation by repressing the expression of inhibitors that prevent the differentiation of neuronal precursors. However, because the expression of hairy-like genes are known to be subject to negative feedback (Takebayashi et al., 1994), these results raise the possibility that Hes6 blocks the activity of the hairy proteins, resulting in an increase in their expression.

The regulation of hairy expression by negative feedback was examined further by assaying the expression of XHairyl in animal caps (Fig. 6E). The level of Xhairyl RNA expressed in isolated Xenopus animal caps is strongly reduced following injection of Xhairy2A RNA, indicating cross-repression by related members of the WRPW-bHLH family. If Xhairyl expression is subject to repression by the hairy proteins, then a hairy protein converted into a transcriptional activator should induce its expression (Jimenez et al., 1996). As predicted, a Xhairy2A/Gal4 fusion protein superinduces the expression of Xhairyl in animal caps (Fig. 6E). Finally, we examined whether Hes6 acts as an inhibitor of this negative feedback repression, by expressing it in animal caps alone or with Xhairy2A. The results show that Hes6 induces the expression 


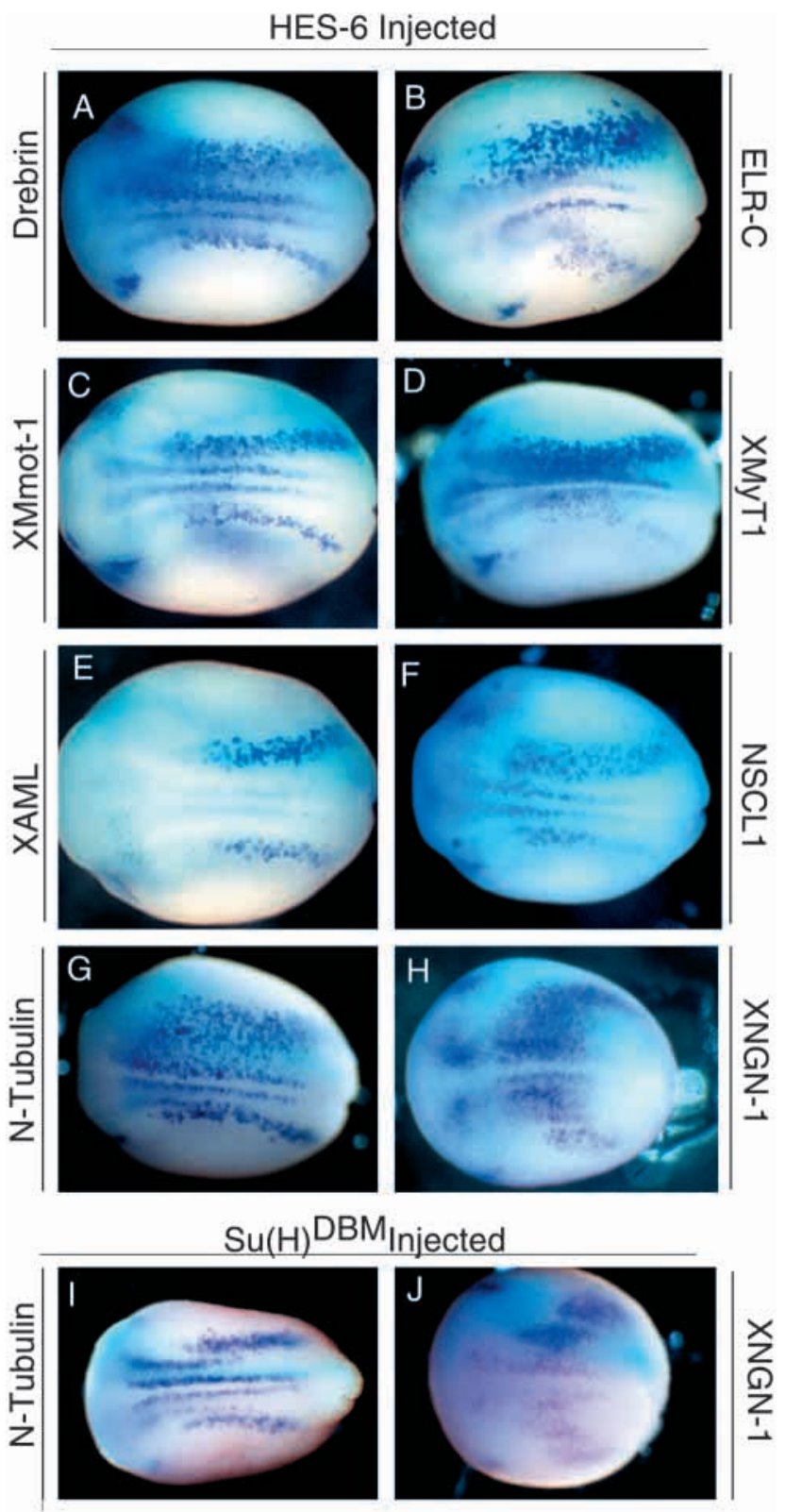

of Xhairyl, and inhibits the ability of Xhairy2A to repress Xhairyl expression (Fig. 6E). Similar results were obtained with a DNA-binding mutant of Hes6 (see below). In sum, these results support the idea that Hes6 acts an inhibitor of hairy protein activity rather than as a repressor of hairy expression.
Fig. 5. Hes6 promotes neuronal differentiation. (A-H) Two-cell-stage embryos were injected with Hes6 RNA along with lacZ RNA as a tracer. Embryos were fixed and stained with X-gal at neural plate stages and then processed for the staining for probes that correspond to various genes expressed during primary neurogenesis as indicated. Hes6 induces an increase in the number of cells expressing Xmyt 1 (11/15 embryos), Drebrin (8/9), Nscl1 (10/10), Xmmot-1 (12/13), Elrc (11/11), N-tubulin 90/108), Xngnl (15/17) and Xaml (10/10). $(\mathrm{I}, \mathrm{J})$ For comparison, embryos were injected with RNA encoding a dominant negative form of $\mathrm{Su}(\mathrm{H}), \mathrm{XSu}(\mathrm{H})^{\mathrm{DBM}}$, and stained with probes of $N$-tubulin and Xngnl (Wettstein et al., 1997). Note that the levels of Xngnl increase on the injected side, but the striped pattern of expression is retained, and that $N$-tubulin-expressing cells subsequently form at a higher density in each stripe.

\section{Hes6 does not need to bind DNA to promote neuronal differentiation}

Mutant forms of Hes6 were generated to determine which domains of the protein are required for promoting neuronal differentiation. In light of the model that Hes6 inhibits the activity of the hairy genes, we tested whether Hes6 acts by binding up the Groucho co-repressor via its terminal WPRWtetrapeptide. Accordingly, a mutant of Hes6 was generated that lacks the terminal WRPW residues and is expressed in embryos. However, this mutant still promotes neuronal differentiation, suggesting that the WRPW motif is dispensable for Hes6 activity (Table 1). Secondly, we tested whether Hes6 requires its DNA-binding domain to promote neuronal differentiation, by generating a mutant of Hes6 in which residues in the basic domain were changed to neutral amino acids (see Materials and Methods). When expressed in embryos, the DNA-binding mutant behaved the same as the wild-type Hes6 protein, in that it promoted neuronal differentiation, ectopic Xngnl expression, and the upregulation of hairy expression, suggesting that DNAbinding is not required for Hes6 activity (Table 1, Fig. 7B). As a further control, we expressed in embryos a similar DNAbinding mutant of Esr7, a WRPW-bHLH protein whose expression is activated by the Notch pathway (see Fig. 3). While wild-type Esr7 strongly inhibits $N$-tubulin expression, the DNA-binding mutant of Esr7 has no effect (Fig. 7C,D). Together these results indicate that Hes6 does not need to bind DNA or the Groucho co-repressors to promote neuronal differentiation, to upregulate the expression of the hairy genes, nor to induce ectopic expression of Xngnl. In addition, the effects of both wild type and the DNA-binding mutant of Hes6 are not mimicked by similar forms of Esr7.

\section{Physical interactions between Hes6 and the hairy proteins}

The results described above indicate that Hes6 may inhibit the

Table 1. Effects of Hes6 and mutants on markers

\begin{tabular}{|c|c|c|c|c|c|c|c|c|c|}
\hline \multirow[b]{2}{*}{ Constructs } & \multicolumn{3}{|c|}{ Tubulin } & \multicolumn{3}{|c|}{ hairy1 } & \multicolumn{3}{|c|}{ hairy2 } \\
\hline & Increase & Decrease & $\mathrm{nc}$ & Increase & Decrease & $\mathrm{nc}$ & Increase & Decrease & $\mathrm{nc}$ \\
\hline Hes6 & $41 / 45$ (91\%) & $1 / 45(2 \%)$ & $3 / 45(7 \%)$ & $53 / 54(98 \%)$ & $0 / 54(0 \%)$ & $1 / 54(2 \%)$ & $39 / 42(93 \%)$ & 0/42 (0\%) & $3 / 42(7 \%)$ \\
\hline Hes 6 DBM & $36 / 45(80 \%)$ & $4 / 45(9 \%)$ & $5 / 45(11 \%)$ & $16 / 21(76 \%)$ & $0 / 21(0 \%)$ & $5 / 21(24 \%)$ & $21 / 26(81 \%)$ & $0 / 26(0 \%)$ & $5 / 26(19 \%)$ \\
\hline lacZ & $12 / 87(14 \%)$ & $6 / 87(7 \%)$ & $69 / 87(79 \%)$ & $9 / 70(13 \%)$ & $0 / 70(0 \%)$ & $61 / 70(87 \%)$ & $0 / 46(0 \%)$ & $0 / 46(0 \%)$ & $46 / 46(100 \%)$ \\
\hline
\end{tabular}

Embryos were injected into one cell at the two-cell stage with the RNAs indicated. At the neural plate stage, embryos were scored for marker expression within the injected side. The number of embryos scored for each phenotype is expressed as a fraction of the total embryos examined. nc, no change in expression. 

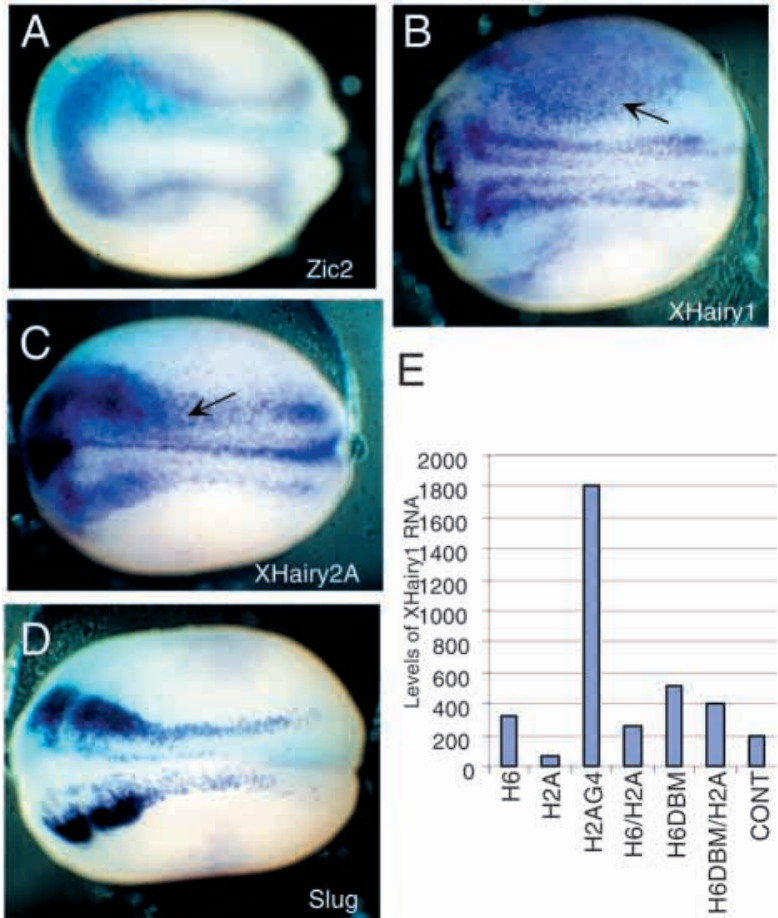

Fig. 6. Hes6 induces the expression of the hairy genes. (A-D) Hes6 was ectopically expressed along with lacZ in Xenopus embryos, which were processed at the neural plate stage as described in the legend to Fig. 3. Note that the expression of both Xhairyl (B, 53/54 embryos) and Xhairy2a (C, 39/42 embryos) is upregulated in response to Hes6, while Zic2 expression (A, 34/37 embryos) and Slug expression (D, 23/30 embryos) do not change appreciably. (E) RNase protection analysis of Xhairyl RNA levels in animal caps injected with RNA encoding Xhairy2a (0.5 ng, H2A), Xhairy2a-Gal4 (0.5 ng, H2AG4), Hes6 (0.5 ng, H6), Xhairy2a and Hes6 (0.5/0.5 ng, H6/H2A), a DNA-binding mutant of Hes6 (2 ng, H6DBM), or both Xhairy2A and a DNA-binding mutant of Hes6 (2/0.5 ng,

H6DBM/H2A). Xhairy1 RNA levels are expressed in arbitrary units after normalizing to the levels of an endogenous control Efl $\alpha$ RNA (Materials and Methods). Note that both Hes6 and Hes6DBM induce Xhairyl expression above that in control animal caps (CONT), while Xhairy2A represses. Hes6 and the DNA-binding mutant reverses the inhibitory effect of Xhairy2a.

activity of the hairy-like proteins. To determine if this mechanism involves a direct physical interaction with the hairy proteins, we tested binding of Hes6 to these proteins both in vitro and in vivo. Hes6 showed binding to both Xhairy2a and Xhairy1 in this assay, consistent with a direct physical interaction (Fig. 8). Binding of Hes6 to the hairy proteins was also tested in embryos, by coexpressing a Myc-tagged form of Hes6, along with His-tagged forms of Xhairy1, Xhairy2a and Esr7. The results indicate that Hes6 binds to both Xhairy1 and Xhairy2a but not significantly to Xesr7 (Fig. 8). Together these results indicate that Hes6 may physically interact with the hairy proteins to inhibit their activity. In addition the results of both assays indicate that Hes6 binds more robustly to the hairy proteins than to itself.

\section{DISCUSSION}

WRPW-bHLH transcription factors have been proposed to act
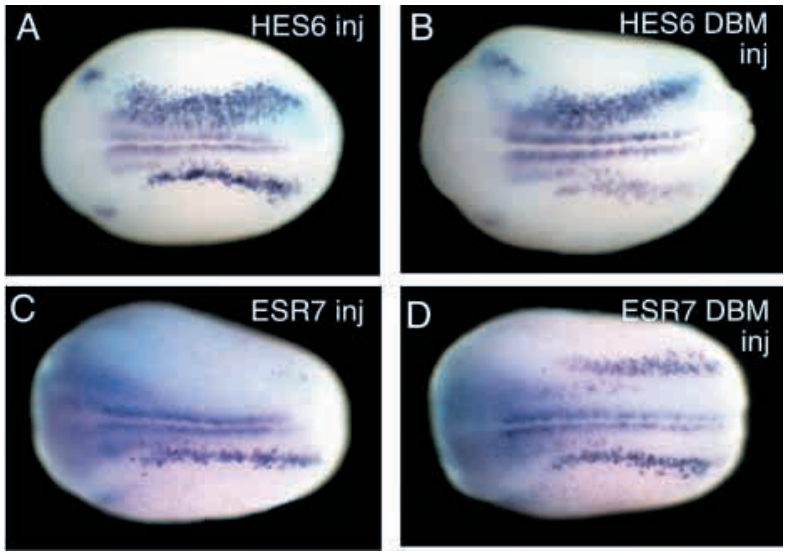

Fig. 7. DNA-binding mutant of Hes6 promotes neuronal differentiation. (A-D) RNAs as indicated were ectopically expressed along with lacZ in Xenopus embryos, which were processed at the neural plate stage as described in the legend to Fig. 3 for $\mathrm{N}$-tubulin expression. Note that Hes6 (23/26 embryos) and the DNA-binding mutant of Hes6 (23/36 embryos) promote neuronal differentiation, while Esr7 inhibits (13/15 embryos). A DNA-binding mutant of Esr7 does not produce significant changes (14/15 embryos unchanged).

as negative regulators of cell differentiation (Fisher and Caudy, 1998). Here we describe a new member of the WRPW-bHLH proteins, called Hes6, whose expression and activity during neurogenesis suggests a role in promoting differentiation. In contrast to other known WRPW-bHLH genes, Hes6 expression during neurogenesis is activated by the proneural bHLH proteins, but not by Notch signaling. Hes6 expression is associated with differentiating neuronal precursors. Finally, ectopic expression of Hes6 does not inhibit, but strongly promotes, neuronal differentiation in Xenopus embryos. These properties make Hes6 suited to act in a positive-feedback loop with the proneural bHLH proteins, thus regulating the transition of determined progenitors into differentiated progeny during vertebrate neural development. We note that mouse Hes6 was independently isolated and analyzed by Bae et al. (2000) and that the results obtained in both studies are in agreement (Bae et al., 2000).

\section{Regulation of Hes6 expression}

In Xenopus, the WRPW-bHLH genes expressed in the developing nervous system fall into two categories based on their response to various transcription factors that act during neurogenesis (Kopan and Turner, 1996). One category includes the hairy-like genes, Xhairyl and Xhairy2a, whose expression in embryos occurs in broad domains that do not change significantly when embryos express an activated form of Notch. Moreover, the expression of the hairy-like genes is not induced in response to the proneural proteins. By contrast, $E(S p l)$-like genes, such as Esrl and Esr7, are expressed in the domains of the neural plate where neurogenesis occurs, and are dramatically upregulated in expression in response to ICD as well as the proneural bHLH proteins (Deblandre et al., 1999; Koyano-Nakagawa et al., 1999; Wettstein et al., 1997). The Esr genes therefore behave similarly to those in the Drosophila $\mathrm{E}(\mathrm{SPL})-\mathrm{C}$, whose promoters contain both $\mathrm{Su}(\mathrm{H})$ and E-box binding sites that are targets of the Notch pathway and the proneural proteins, respectively (Nellesen et al., 1999). In 

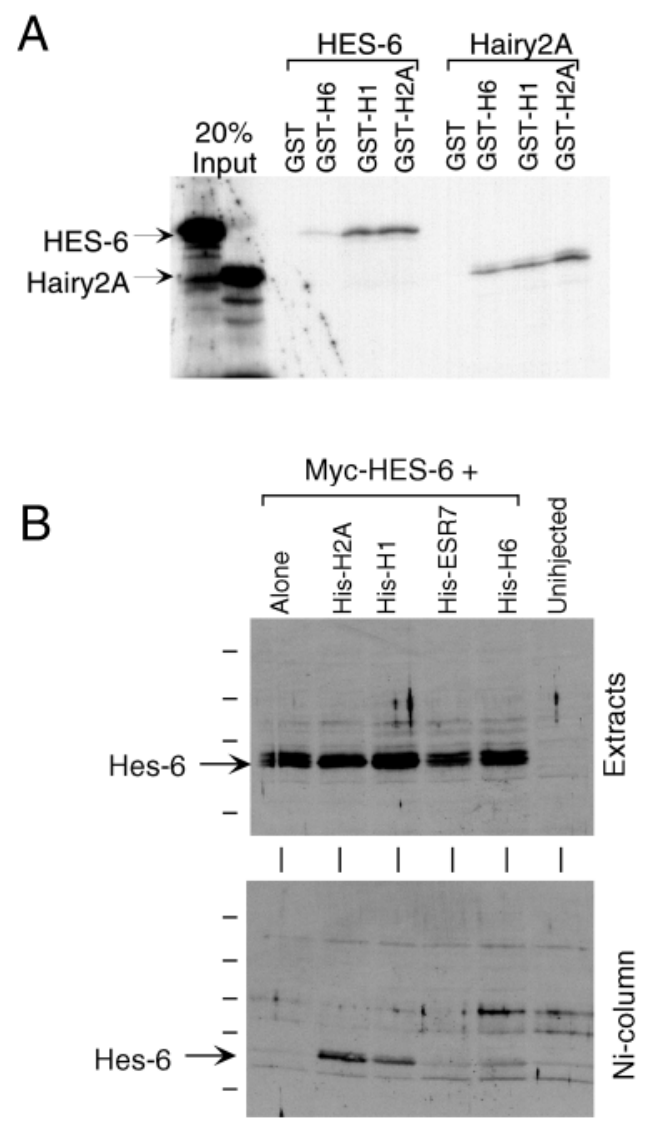

Fig. 8. Physical interactions between Hes6 and the hairy proteins. (A) Equivalent amounts of GST fusion protein bound to beads were incubated with ${ }^{35} \mathrm{~S}$-labeled Hes6 and Xhairy $2 \mathrm{~A}$ and washed; the bound proteins were detected by gel electrophoresis and autoradiography (see Materials and Methods). $20 \%$ of the ${ }^{35} \mathrm{~S}$ labelled Hes6 and Xhairy2A added to each binding reaction is shown on the left, and the bound proteins are shown on the right. Note that both Hes6 and Xhairy2A do not show appreciable binding to GST alone, but bind to varying extents to each other. Notably Hes6 binds better to the hairy proteins than to itself, while Xhairy2A binds to all proteins. (B) Embryos were injected with RNA encoding a Myctagged form of Hes6 alone, or along with RNA encoding His-tagged forms of Xhairy2A, Xhairy1, Esr7 or Hes6. Note that Hes6 binds to both His-tagged Xhairy2a (H2A), and Xhairy1 (H1), but not to Esr7, or to itself.

contrast to the Esr genes, Hes6 expression is not upregulated by ICD nor blocked by $\mathrm{X}-\mathrm{Su}(\mathrm{H})^{\mathrm{DBM}}$, suggesting strongly that it is not a target of the Notch pathway. Conversely, expression of Hes6 is positively regulated by the proneural genes. While the expression of Esrl and Esr7 can be induced by the proneural proteins, this regulation may be non cell autonomous, as the proneural proteins induce the expression of Xdeltal (Koyano-Nakagawa et al., 1999). As Hes6 is not activated by the Notch pathway, it is much more likely that the proneural proteins activate its expression cell autonomously. Finally, Hes6 expression apparently requires neurogenin activity as the expression of Hes6 is lost in the progenitor cells of the proximal cranial ganglia in Ngnl mutant mice. From these data, we conclude that Hes6 expression, in contrast to that of the other WRPW-bHLH genes, is principally driven by the bHLH factors in association with neuronal differentiation, rather than by the Notch pathway in association with lateral inhibition.

In mouse embryos, Hes6 expression in the developing nervous system is detected at low levels in the ventricular zone along with the determinative bHLH proteins and at high levels in the intermediate zone along with the differentiation bHLH proteins, such as NeuroD. In addition, Hes6 expression follows that of the neurogenins, and coincides with that of NeuroD during the onset of neurogenesis within the DRG of mouse, or during primary neurogenesis in Xenopus. These temporal and spatial features of Hes6 expression are more consistent with a role in promoting the transition of neural progenitor cells to their differentiated neuronal progeny, rather than in later aspects of neuronal differentiation. One can also associate Hes6 expression with the determinative phase of neurogenesis by the fact that its expression in Xenopus embryos is readily induced by Xash3, a proneural protein related to Drosophila achaete and scute (Turner and Weintraub, 1994; Zimmerman et al., 1993). Previous studies have shown that injection of Xash3 RNA can activate a subset of the genes expressed during early neurogenesis, including those that mediate lateral inhibition. However as a result of lateral inhibition, Xash3 does not efficiently activate many of the critical downstream target genes required for differentiation such as Xmytl and NeuroD (Bellefroid et al., 1996). The strong response of Hes6 expression to Xash3 is therefore a further indication that its expression follows closely that of proneural gene activity, in association with the determinative phases of neurogenesis.

\section{Hes 6 promotes neuronal differentiation}

In contrast to other WRPW-bHLH proteins such as Xenopus Esr1, Esr7, mouse Hes1 and Zebrafish Her4, ectopic expression of Hes6 does not inhibit, but rather promotes neuronal differentiation (Ishibashi et al., 1994; Takke et al., 1999). Specifically, in Xenopus embryos, Hes6 expression by RNA injection induces increased numbers of neurons across the posterior neural plate, resulting in a higher density of neuronal differentiation than normal and ectopic neuronal differentiation between the stripes where $N$-tubulin-expressing cells normally form. Similar increases in neuronal differentiation are also induced by Hes6 in the trigeminal placode. The induction of ectopic neurons by Hes6 is evidenced by the increase in the number of cells expressing a spectrum of genes that are activated by Xngn1 and likely to be required for differentiation such as Xmytl, Xath3 and NeuroD as well as a number of other genes that mark the early phases of neuronal differentiation. Thus, in contrast to other WRPWbHLH proteins, the properties of ectopically expressed Hes6 suggests a role in promoting the differentiation of progenitor cells into neurons. This suggestion is further supported by tracing the fate of Hes6-expressing cells in the mouse using the perdurance of a lacZ reporter knocked into the Hes6 gene. Hes6 expressing cells give rise to neurons, rather than the glial cells that would have been expected if Hes6 were involved in inhibiting neurogenesis.

Significantly, Hes6 promotes neuronal differentiation only when ectopically expressed in Xenopus in regions of the neural plate where Xngnl is already expressed. This finding coupled with the expression pattern of Hes6 leads us to propose that Hes6 functions primarily by promoting neuronal differentiation in neuronal progenitors that already express the 
neurogenins. Hes6 might act, for example, by allowing the neurogenins to activate more effectively the expression of downstream bHLH proteins required for neuronal differentiation. Alternatively Hes6 might also act by increasing the expression levels of the neurogenins, thus increasing the likelihood that cells will be driven to differentiate. This latter possibility is supported by the observation that Hes6 induces the expression of Xngnl within the Xenopus neural plate. Under normal circumstances, the expression of Xngnl in the posterior neural plate occurs in a pattern that prefigures the stripes and interstripes of neuronal differentiation. This pattern of Xngnl expression, however, is much broader and diffuse than the final pattern of $N$-tubulin expressing cells. Hes6 induces an even more uniform pattern of Xngnl expression that predicts the subsequent uniform pattern of neuronal differentiation. Thus, Hes6 may promote neuronal differentiation by increasing both the expression of Xngnl as well as its activity.

\section{Hes 6 may promote neuronal differentiation by several mechanisms}

The mechanism by which Hes6 promotes the differentiation of neurogenin-expressing progenitor cells remains an unanswered question. Based on its structural features as a transcriptional repressor, one likely model is that Hes6 binds target sites and represses the expression of genes that normally act to inhibit neuronal differentiation. The main argument against this model is that Hes6 still promotes neuronal differentiation even when its DNA-binding domain is mutant, or the WRPW motif is deleted. However, this argument is inconclusive as there are several published examples in which WRPW-bHLH proteins act as wild-type molecules, even when their DNA-binding or WRPW domains are removed (Dawson et al., 1995; Giebel and Campos-Ortega, 1997; Jimenez et al., 1996; Takke et al., 1999). As further support of this model, the expression of Xngnl and neuronal differentiation are repressed by a form of Hes6 that was converted from a transcriptional repressor into a transcription activator by substituting the WRPW domain with the activation domain of VP16 (data not shown). The simplest interpretation of this result is that this form of Hes6 induces the expression of repressors that inhibit neuronal differentiation, while, by extension, Hes6 would normally repress this repressors. If Hes6 normally acts as a transcriptional repressor, it does not promote neuronal differentiation by repressing the expression of genes in the lateral inhibitory pathway such as Xdeltal and the Esr genes, or other proposed repressors of neuronal differentiation such as the hairy-like genes or Zic2. This implies that Hes6 represses the expression of a novel class of repressors that negatively regulate the expression and activity of the proneural bHLH proteins.

An alternative, but not mutually exclusive, model is based on the striking induction of Hairy gene expression by Hes6. Because the expression of the Hairy genes is repressed by their own products (Takebayashi et al., 1994), the simplest interpretation of this result is that Hes6 inhibits the activity of these WRPW-bHLH proteins post-transcriptionally. In support of this possibility, Hes6 induces the expression of Xhairyl in an animal cap assay. Moreover in the same assay, Xhairy2A represses Xhairyl expression, and this effect can be reversed by co-injection of Hes6 RNA. Finally, Hes6 can bind to the hairy proteins both in vitro and in vivo. These observations raise the possibility that Hes6 inhibit hairy protein activity by forming, for example, nonfunctional heterodimers with the hairy-like proteins, in much the same way that the Ids heterodimerize with and inhibit the positive acting bHLHs. Hes6 could also compete for accessory molecules that are required for repression by the hairy proteins, although this is not likely to be the Groucho co-repressors, as the WRPWdeletion mutant of Hes6 retains wild-type activity. Conversely, a Esr7 mutant containing the WRPW but lacking the DNAbinding domain is apparently inactive when overexpressed, indicating that overexpression of the WRPW domain is not sufficient to promote neuronal differentiation. Regardless of the exact mechanistic details, the ability of Hes6 to interfere with the activity of these proteins raises the possibility that the hairy class of proteins is one target disabled by Hes6 when it promotes neuronal differentiation.

\section{A model for Hes6 regulation of neuronal differentiation}

The two key findings of our results are that the expression of Hes6 is promoted by the neurogenins, and that Hes6 promotes the differentiation of neurogenin-expressing cells into neurons. These findings suggest a model where Hes6 regulates neurogenesis by mediating a positive-feedback loop with the proneural bHLH proteins that promotes neuronal differentiation. Positive-feedback loops that lock cells into a differentiated state have previously been described for the myogenic bHLH transcription factors (reviewed in (Yun and Wold, 1996)). For example, MyoD, which plays a determinative role during myogenesis, activates its own expression as well as that of downstream myogenic bHLH proteins, such as myogenin. Similar autoregulation has been described for the neural bHLH proteins. In Xenopus, for example, the downstream bHLH genes such as NeuroD and Xath3 are not only activated by Xngn 1 but also by themselves (Ma et al., 1996; Perron et al., 1999). In the mouse the Math1 promoter has been shown to contain E-box-binding sites that are activated by the proneural bHLH proteins and required for its expression (Helms et al., 2000). We propose that Hes6 participates in positive feedback loops with the bHLH proteins: when its expression is induced by the proneural proteins it acts to inhibit the expression/activity of repressors that would normally prevent the proneural proteins from activating their own or each other's expression. In addition, there are cases where the neural bHLH proteins, such as the neurogenins and the Ash proteins, do not activate their own expression. Autoactivation does not appear to play a major role in Mashl expression, as indicated by the analysis of its expression in a Mash1 mutant background (Horton et al., 1999). In Xenopus, ectopic expression of Xngn1, Xath3 or NeuroD does not induce the expression of Xngnl, suggesting that its expression is not regulated by proneural bHLH proteins. However, Hes6 can induce the expression of Xngnl, suggesting another type of positive-feedback loop where low levels of neurogenin/Ash gene activity promotes Hes6 expression, which in turn reduces the activity of inhibitory proteins that repress neurogenin/Ash expression. This loop, in principle, increases the levels of neurogenin gene expression to a threshold required for activating the expression of downstream bHLH proteins required for differentiation. 
Our results have focused on the nervous system, although we note that Hes6 might also play a role in myogenesis. Expression of Hes6 in Xenopus occurs in the tailbud domain, in pattern consistent with a role in myogenesis or segmentation, while in the mouse Hes6 expression appears in the myotome around the stage myogenesis occurs. The role of Hes6 in myogenesis, and a test of its role in neurogenesis await further investigation, and the analysis of mice with targeted mutations in the Hes6 gene.

The authors thank Dr Elise Lamar for helpful and careful comments on the manuscript. We thank P. Mombaerts for the tau-lacZ plasmid, J. Lee for the NeuroD probe, A. Ruiz i Altaba for Xenopus Zic2 probe, J. Gurdon for Xenopus E12 plasmid, K. Kuhlbrodt and M. Wegner for the Sox10 probe, Shirley Pease for performing blastocyst injections, and the staff of the Caltech Transgenic Facility for mouse care. We thank Dr Wui-Chuong Jen for the generation of the hairy2A and the hairy2A-Gal4 expression constructs, and Dr H. U. Wang for early contributions to the isolation of Hes6. D. J. A. is an investigator of the Howard Hughes Medical Institute. The work reported here was supported in part by the Human Frontier Science Program, the Uehara Memorial Foundation (N. K.-N.), and by a grant from NIH (C. K.).

\section{REFERENCES}

Bae, S., Bessho, Y., Hojo, M. and Kageyama, R. (2000). The bHLH gene Hes6, an inhibitor of Hes1, promotes neuronal differentiation. Development 127, 2933-2943.

Bao, J., Talmage, D. A., Role, L. W. and Gautier, J. (2000). Regulation of neurogenesis by interactions between HEN1 and neuronal LMO proteins. Development 127, 425-435.

Bellefroid, E. J., Bourguignon, C., Hollemann, T., Ma, Q., Anderson, D. J., Kintner, C. and Pieler, T. (1996). X-MyT1, a Xenopus C2HC-type zinc finger protein with a regulatory function in neuronal differentiation. Cell 87, 1191-1202.

Ben-Arie, N., Bellen, H. J., Armstrong, D. L., McCall, A. E., Gordadze, P. R., Guo, Q., Matzuk, M. M. and Zoghbi, H. Y. (1997). Math1 is essential for genesis of cerebellar granule neurons. Nature 390, 169-172.

Birren, S. J., Lo, L. and Anderson, D. J. (1993). Sympathetic neuroblast undergo a developmental switch in trophic dependence. Development 119, 597-610.

Blader, P., Fischer, N., Gradwohl, G., Guillemont, F. and Strahle, U. (1997). The activity of neurogenin 1 is controlled by local cues in the zebrafish embryo. Development 124, 4557-4569.

Brewster, R., Lee, J. and Ruiz i Altaba, A. (1998). Gli/Zic factors pattern the neural plate by defining domains of cell differentiation. Nature 393 , 579583.

Castella, P., Wagner, J. A. and Caudy, M. (1999). Regulation of hippocampal neuronal differentiation by the basic helix- loop-helix transcription factors HES-1 and MASH-1. J. Neurosci. Res. 56, 229-240.

Chitnis, A., Henrique, D., Lewis, J., Ish-Horowicz, D. and Kintner, C. (1995). Primary neurogenesis in Xenopus embryos regulated by a homologue of the Drosophila neurogenic gene Delta. Nature 375, 761-766.

Coffman, C. R., Skoglund, P., Harris, W. A. and Kintner, C. R. (1993). Expression of an extracellular deletion of Xotch diverts cell fate in Xenopus embryos. Cell 73, 659-671.

Dawson, S. R., Turner, D. L., Weintraub, H. and Parkhurst, S. M. (1995). Specificity for the hairy/enhancer of split basic helix-loop-helix (bHLH) proteins maps outside the bHLH domain and suggests two separable modes of transcriptional repression. Mol. Cell Biol. 15, 6923-6931.

Deblandre, G. A., Wettstein, D. A., Koyano-Nakagawa, N. and Kintner, C. (1999). A two-step mechanism generates the spacing pattern of the ciliated cells in the skin of Xenopus embryos. Development 126, 4715-4728.

Detrick, R. J., Dickey, D. and Kintner, C. R. (1990). The effect of N-cadherin misexpression on morphogenesis in Xenopus embryos. Neuron 4, 493-506.

Dubois, L., Bally-Cuif, L., Crozatier, M., Moreau, J., Paquereau, L. and Vincent, A. (1998). XCoe2, a transcription factor of the Col/Olf-1/EBF family involved in the specification of primary neurons in Xenopus. Curr. Biol. 8, 199-209.
Farah, M. H., Olson, J. M., Sucic, H. B., Hume, R. I., Tapscott, S. J. and Turner, D. L. (2000). Generation of neurons by transient expression of neural bHLH proteins in mammalian cells. Development 127, 693-702.

Fedtsova, N. G. and Turner, E. E. (1995). Brn-3.0 expression identified early post-mitotic CNS neurons and sensory neural precursors. Mech. Dev. 53, 291-304.

Ferreiro, B., Kintner, C., Zimmerman, K., Anderson, D. and Harris, W. A. (1994). XASH genes promote neurogenesis in Xenopus embryos. Development 120, 3649-3655.

Fisher, A. and Caudy, M. (1998). The function of hairy-related bHLH repressor proteins in cell fate decisions. BioEssays 20, 298-306.

Fode, C., Gradwohl, G., Morin, X., Dierich, A., LeMeur, M., Goridis, C. and Guillemot, F. (1998). The bHLH protein NEUROGENIN 2 is a determination factor for epibranchial placode-derived sensory neurons. Neuron 20, 483-494.

Frangioni, J. V. and Neel, B. G. (1993). Solubilization and purification of enzymatically active glutathione S- transferase (pGEX) fusion proteins. Anal. Biochem. 210, 179-187.

Gerety, S. S., Wang, H. U., Chen, Z. and Anderson, D. J. (1999). Symmetric mutant phenotypes of the receptor EphB4 and its specific transmembrane ligand ephrin-B2 in cardiovascular development. Mol. Cell 4, 403-414.

Giebel, B. and Campos-Ortega, J. A. (1997). Functional dissection of the Drosophila enhancer of split protein, a suppressor of neurogenesis. Proc. Natl. Acad. Sci. USA 94, 6250-6254.

Good, P. J. (1995). A conserved family of elav-like genes in vertebrates. Proc. Natl. Acad. Sci. USA 92, 4557-4561.

Guillemot, F., Lo, L. C., Johnson, J. E., Auerbach, A., Anderson, D. J. and Joyner, A. L. (1993). Mammalian achaete-scute homolog 1 is required for the early development of olfactory and autonomic neurons. Cell 75, 463-476.

Harland, R. M. (1991). In situ hybridization: an improved whole-mount method for Xenopus embryos. Methods Cell Biol. 36, 685-695.

Helms, A. W., Abney, A. L., Ben-Arie, N., Zoghbi, H. Y. and Johnson, J. E. (2000). Autoregulation and multiple enhancers control Math1 expression in the developing nervous system. Development 127, 1185-1196.

Horton, S., Meredith, A., Richardson, J. A. and Johnson, J. E. (1999). Correct coordination of neuronal differentiation events in ventral forebrain requires the bHLH factor MASH1. Mol. Cell. Neurosci. 14, 355-369.

Ishibashi, M., Ang, S. L., Shiota, K., Nakanishi, S., Kageyama, R. and Guillemot, F. (1995). Targeted disruption of mammalian hairy and Enhancer of split homolog-1 (HES-1) leads to up-regulation of neural helixloop-helix factors, premature neurogenesis, and severe neural tube defects. Genes Dev. 9, 3136-3148.

Ishibashi, M., Moriyoshi, K., Sasai, Y., Shiota, K., Nakanishi, S. and Kageyama, R. (1994). Persistent expression of helix-loop-helix factor HES1 prevents mammalian neural differentiation in the central nervous system. EMBO J. 13, 1799-1805.

Jen, W. C., Gawantka, V., Pollet, N., Niehrs, C. and Kintner, C. (1999). Periodic repression of Notch pathway genes governs the segmentation of Xenopus embryos. Genes Dev. 13, 1486-1499.

Jen, Y. and et al. (1992). Overexpression of Id protein inhibits the muscle differentiation program: in vivo association of Id with E2A proteins. Genes Dev. 6, 1466-1479.

Jimenez, G., Pinchin, S. M. and Ish-Horowicz, D. (1996). In vivo interactions of the Drosophila Hairy and Runt transcriptional repressors with target promoters. EMBO J 15, 7088-7098.

Kintner, C. R. and Dodd, J. (1991). Hensen's node induces neural tissue in Xenopus ectoderm. Implications for the action of the organizer in neural induction. Development 113, 1495-1505.

Knecht, A. K., Good, P. J., Dawid, I. B. and Harland, R. M. (1995). Dorsalventral patterning and differentiation of noggin-induced neural tissue in the absence of mesoderm. Development 121, 1927-1935.

Kopan, R. and Turner, D. L. (1996). The Notch pathway: democracy and aristocracy in the selection of cell fate. Curr. Opin. Neurobiol. 6, 594-601.

Koyano-Nakagawa, N., Wettstein, D. and Kintner, C. (1999). Activation of Xenopus genes required for lateral inhibition and neuronal differentiation during primary neurogenesis. Mol. Cell. Neurosci. 14, 327-339.

Kuhlbrodt, K., Herbarth, B., Sock, E., Hermans-Borgmeyer, I. and Wegner, M. (1998). Sox 10, a novel transcriptional modulator in glial cells. J. Neurosci. 18, 237-250.

Lee, J. E. (1997). Basic helix-loop-helix genes in neural development. Curr. Opin. Neurobiol. 7, 13-20.

Lee, J. E., Hollenberg, S. M., Snider, L., Turner, D. L., Lipnick, N. and Weintraub, H. (1995). Conversion of Xenopus ectoderm into neurons by NeuroD, a basic helix- loop-helix protein. Science 268, 836-844. 
Lu, J., Webb, R., Richardson, J. A. and Olson, E. N. (1999). MyoR: a muscle-restricted basic helix-loop-helix transcription factor that antagonizes the actions of MyoD. Proc. Natl. Acad. Sci. USA 96, 552-557.

Lyden, D., Young, A. Z., Zagzag, D., Yan, W., Gerald, W., O'Reilly, R., Bader, B. L., Hynes, R. O., Zhuang, Y., Manova, K. et al. (1999). Id1 and Id3 are required for neurogenesis, angiogenesis and vascularization of tumour xenografts. Nature 401, 670-677.

Ma, Q., Chen, Z., del Barco Barrantes, I., de la Pompa, J. L. and Anderson, D. J. (1998). neurogenin1 is essential for the determination of neuronal precursors for proximal cranial sensory ganglia. Neuron 20, 469-482.

Ma, Q., Kintner, C. and Anderson, D. J. (1996). Identification of neurogenin, a vertebrate neuronal determination gene. Cell 87, 43-52.

Mayor, R., Morgan, R. and Sargent, M. G. (1995). Induction of the prospective neural crest of Xenopus. Development 121, 767-777.

Modolell, J. (1997). Patterning of the adult peripheral nervous system of Drosophila. Perspect. Dev. Neurobiol. 4, 285-296.

Mombaerts, P., Wang, F., Dulac, C., Chao, S. K., Nemes, A., Mendelsohn, M., Edmondson, J. and Axel, R. (1996). Visualizing an olfactory sensory map. Cell 87, 675-686.

Nakamura, Y., Sakakibara, S., Miyata, T., Ogawa, M., Shimazaki, T., Weiss, S., Kageyama, R. and Okano, H. (2000). The bHLH gene hes1 as a repressor of the neuronal commitment of CNS stem cells. J. Neurosci. 20, 283-293.

Nellesen, D. T., Lai, E. C. and Posakony, J. W. (1999). Discrete enhancer elements mediate selective responsiveness of enhancer of split complex genes to common transcriptional activators. Dev. Biol. 213, 33-53.

Nieuwkoop, P. D. and Faber, J. (1967). Normal table of Xenopus Laevis. Amsterdam: North Holland.

Oschwald, R., Richter, K. and Grunz, H. (1991). Localization of a nervous system-specific class II beta-tubulin gene in Xenopus laevis embryos by whole-mount in situ hybridization. Int. J. Dev. Biol. 35, 399-405.

Perez, S. E., Rebelo, S. and Anderson, D. J. (1999). Early specification of sensory neuron fate revealed by expression and function of neurogenins in the chick embryo. Development 126, 1715-1728.

Perron, M., Opdecamp, K., Butler, K., Harris, W. A. and Bellefroid, E. J. (1999). X-ngnr-1 and Xath3 promote ectopic expression of sensory neuron markers in the neurula ectoderm and have distinct inducing properties in the retina. Proc. Natl. Acad. Sci. USA 96, 14996-15001.

Postigo, A. A. and Dean, D. C. (1997). ZEB, a vertebrate homolog of Drosophila $\mathrm{Zfh}-1$, is a negative regulator of muscle differentiation. $E M B O$ J. 16, 3935-3943.

Sasai, Y., Kageyama, R., Tagawa, Y., Shigemoto, R. and Nakanishi, S. (1992). Two mammalian helix-loop-helix factors structurally related to Drosophila hairy and Enhancer of split. Genes Dev. 6, 2620-2634.

Schmidt, J., Francois, V., Bier, E. and Kimelman, D. (1995). Drosophila short gastrulation induces an ectopic axis in Xenopus: evidence for conserved mechanisms of dorsal-ventral patterning. Development 121, 4319-4328.

Spicer, D. B., Rhee, J., Cheung, W. L. and Lassar, A. B. (1996). Inhibition of myogenic bHLH and MEF2 transcription factors by the bHLH protein Twist. Science 272, 1476-1480.

Stein, R., Mori, N., Matthews, K., Lo, L. C. and Anderson, D. J. (1988).
The NGF-inducible SCG10 mRNA encodes a novel membrane-bound protein present in grouwth cones and abundant in developing neurons. Neuron 1, pp. 463-476.

Strom, A., Castella, P., Rockwood, J., Wagner, J. and Caudy, M. (1997). Mediation of NGF signaling by post-translational inhibition of HES-1, a basic helix-loop-helix repressor of neuronal differentiation. Genes Dev. 11, 3168-3181.

Takebayashi, K., Sasai, Y., Sakai, Y., Watanabe, T., Nakanishi, S. and Kageyama, R. (1994). Structure, chromosomal locus, and promoter analysis of the gene encoding the mouse helix-loop-helix factor HES-1. Negative autoregulation through the multiple $\mathrm{N}$ box elements. J. Biol. Chem. 269, 5150-5156.

Takebayashi, K., Takahashi, S., Yokota, C., Tsuda, H., Nakanishi, S., Asashima, M. and Kageyama, R. (1997). Conversion of ectoderm into a neural fate by ATH-3, a vertebrate basic helix-loop-helix gene homologous to Drosophila proneural gene atonal. EMBO J. 16, 384-395.

Takke, C. and Campos-Ortega, J. A. (1999). her1, a zebrafish pair-rule like gene, acts downstream of notch signalling to control somite development. Development 126, 3005-3014.

Takke, C., Dornseifer, P., v. Weizsacker, E. and Campos-Ortega, J. A. (1999). her4, a zebrafish homologue of the Drosophila neurogenic gene E(spl), is a target of NOTCH signalling. Development 126, 18111821.

Tracey, W. D. Jr, Pepling, M. E., Horb, M. E., Thomsen, G. H. and Gergen, J. P. (1998). A Xenopus homologue of aml-1 reveals unexpected patterning mechanisms leading to the formation of embryonic blood. Development $\mathbf{1 2 5}$, 1371-1380.

Turner, D. L. and Weintraub, H. (1994). Expression of achaete-scute homolog 3 in Xenopus embryos converts ectodermal cells to a neural fate. Genes Dev. 8, 1434-1447.

Van Doren, M., Bailey, A. M., Esnayra, J., Ede, K. and Posakony, J. W. (1994). Negative regulation of proneural gene activity: hairy is a direct transcriptional repressor of achaete. Genes Dev. 8, 2729-2742.

Van Doren, M., Powell, P. A., Pasternak, D., Singson, A. and Posakony, J. W. (1992). Spatial regulation of proneural gene activity: auto- and crossactivation of achaete is antagonized by extramacrochaetae. Genes Dev. 6, 2592-2605.

Wettstein, D. A., Turner, D. L. and Kintner, C. (1997). The Xenopus homolog of Drosophila Suppressor of Hairless mediates Notch signaling during primary neurogenesis. Development 124, 693-702.

Xiang, M. Q., Zhou, L. J., Macke, J. P., Yoshioka, T., Hendry, S. H. C., Eddy, R. L., Shows, T. B. and Nathans, J. (1995). The Brn-3 family of POU-domain factors - primary structure, binding specificity, and expression in subsets of retinal ganglion-cells and somatosensory neurons. J. Neurosci. 15, 4762-4785.

Yun, K. and Wold, B. (1996). Skeletal muscle determination and differentiation: story of a core regulatory network and its context. Curr. Opin. Cell. Biol. 8, 877-889.

Zimmerman, K., Shih, J., Bars, J., Collazo, A. and Anderson, D. J. (1993). XASH-3, a novel Xenopus achaete-scute homolog, provides an early marker of planar neural induction and position along the mediolateral axis of the neural plate. Development 119, 221-232. 